\title{
A Biodegradable Polymer-based Coating to Control the Performance of Magnesium Alloy Orthopaedic Implants
}

\author{
K.H.M. Wong ${ }^{\text {a\# }}$; K.W.K. Yeung ${ }^{\text {a\#} ; \text { J.K.O. Lam }}{ }^{\text {a }}$ V. Tam ${ }^{\text {a }}$ P.K. Chub ; K.D.K. \\ Luk $^{\mathrm{a}}$; K.M.C. Cheung ${ }^{\mathrm{a}}$ \\ ${ }^{a}$ Department of Orthopaedics and Traumatology, The University of Hong Kong, \\ Pokfulam, Hong Kong, China \\ b Department of Physics and Materials Science, City University of Hong Kong, \\ Kowloon, Hong Kong, China \\ \# The first two authors share the co-first authorship \\ * Corresponding author
}

\begin{abstract}
Magnesium and its alloys may potentially be applied as degradable metallic materials in orthopaedic implantations due to their degradability and resemblance to human cortical bone. However, the high corrosion rate and accumulation of hydrogen gas upon degradation hinders its clinical application. In this study, we adopt a new approach to control the corrosion rate by coating a controllable polymeric membrane fabricated by polycaprolactone and dichloromethane onto magnesium alloys, in which
\end{abstract}


pore size was controlled during the manufacturing process. The addition of the polymeric membrane was found to reduce the degradation rate of magnesium, and the bulk mechanical properties were shown to be maintained upon degradation. The invitro studies indicated good cytocompatibility of eGFP and SaOS-2 osteoblasts with the polymer-coated samples, which was not observed for the uncoated samples. The in-vivo study indicated that the uncoated sample degraded more rapidly than that of the polymer-coated samples. Although new bone formation was found on both samples, as determined by Micro-CT, higher volumes of new bone were observed on the polymer-coated samples. Histological analysis indicated no inflammation, necrosis or hydrogen gas accumulation on either of the samples during degradation. Collectively, these data suggest that the use of polymeric membrane may be potentially applied for future clinical use.

Keywords: magnesium; polycaprolactone; biodegradable; corrosion; biocompatibility

\section{Introduction}

The most commonly used materials for bone fracture fixation are usually made of medical-grade metals such as $316 \mathrm{~L}$ stainless steel, pure titanium and its alloys, and cobalt-chromium-based alloys [1, 2] which are non-biodegradable. However, one desirable characteristic of an implant is its ability to be degraded after the bone has 
healed as problems may arise if the implants are not degradable. Long term adverse effects or even an increased risk of local inflammation may occur after long-term implantation since the metallic implant is a foreign body to human tissues [3]. If this is the case, second surgery is subsequently conducted for implant removal. However, repeated surgery not only increases the morbidity rate of the patients, but also results in an increase of health care costs and longer hospitalization [1]. To reduce such complications, the use of biodegradable metallic implants has been investigated $[1,4-$ 7].

Magnesium and its alloys are the most commonly used metal amongst all the degradable metallic materials. However, the major obstacles of the clinical use of magnesium-based materials are its rapid degradation rate and the release of hydrogen gas upon degradation $[8,9]$. Troitskii and Tsitrin used a magnesium-cadmium alloy to secure various fractures, however, reported that the mechanical integrity of the magnesium alloy was only maintained for 6-8 weeks with the release of hydrogen during the corrosion process [10]. Hence, in order to make use of magnesium-based materials feasible for surgical implantation, the corrosion rate must be controlled.

The enhancement of the corrosion resistance of magnesium can be achieved by using different modification methods such as alloying [11] and various surface treatments [12]. Witte et al. $[4,12]$ suggested that magnesium alloys, especially those 
containing rare earth elements seemed to be suitable for use as orthopaedic implants.

However, in addition to the alteration of its original mechanical properties, the addition of rare earth metals such as zirconium and cerium into the magnesium substrate may potentially add toxic effects to cells $[13,14]$, as the cytocompatibility of these elements is not known. In the studies by Li et al. (2008) [5], Zhang et al. (2009) [15] and Zberg et al. (2009) [16]; a magnesium-calcium alloy, magnesium-zinc alloy and magnesium-zinc-calcium alloys, were fabricated respectively and used as biodegradable implants, however, the change in mechanical properties of these alloys during degradation were not addressed.

Apart from alloying, surface modifications such as micro-arc oxidation (MAO), ion implantation and plasma anodisation to improve the corrosion properties of magnesium alloys have been investigated [17-22]. Electrochemical tests were conducted with those surface-treated samples, and an increase in corrosion resistance was reported [17-22], however, as the biological integrity of those surface-treated samples was not reported, there was insufficient data to draw any conclusion before applying in clinical use.

In this paper, we improve the properties of magnesium implants via the deposition of a biodegradable polymer-based porous membrane made of polycaprolactone (PCL) and dichloromethane (DCM) onto a commercially available magnesium alloy in order 
to control its degradation rate. This paper aims at investigating the feasibility of these polymeric membranes in controlling the degradation of magnesium alloy under invitro and in-vivo conditions, and addresses the cytocompatibility and mechanical integrity of the deposited samples during degradation.

\section{Materials and methods}

\subsection{Sample preparation}

An AZ91 magnesium ingot with 9 wt $\%$ aluminium and $1 \mathrm{wt} \%$ zinc (Jiaozuo City Anxin Magnesium Alloys Scientific Technology Co., Ltd.) was used in this study. Disc samples which were $5 \mathrm{~mm}$ in diameter and $4 \mathrm{~mm}$ in thickness were prepared for the electrochemical corrosion test, immersion test and in-vitro studies while rod samples were prepared for the mechanical integrity testing and in-vivo animal study. The rod samples for mechanical testing were $3 \mathrm{~mm}$ in diameter and $9 \mathrm{~mm}$ in length whereas for the in-vivo animal study, were $3 \mathrm{~mm}$ in diameter and $6 \mathrm{~mm}$ in length. All the samples were ground and then polished to remove the oxide. Afterwards, they were ultrasonically cleaned with ethanol before conducting the deposition process.

The deposit material was prepared by mixing polycaprolactone (PCL) (SigmaAldrich, USA) with the average molecular weight $\mathrm{Mn} \sim 80,000 \mathrm{~g} / \mathrm{mol}$ and dichloromethane (DCM) (Fisher chemicals, England). Two different concentrations of 
deposit material containing either 3.33\% (w/v) PCL or 2.5\% (w/v) PCL in solvent were applied in order to fabricate various porous sizes and porosities. After the mixture was prepared, the polymer-based membrane was deposited layer by layer on the sample surface by a custom designed spraying device. The device was equipped with air flow and temperature control, thereby standardizing the thickness, homogeneity and adhesiveness of the polymer-based membrane. The air-flow pressure and spraying temperature were $276 \mathrm{kPa}$ and $37^{\circ} \mathrm{C}$, respectively. The spraying process was confined at the conditions of $50 \%$ humidity, $22^{\circ} \mathrm{C}$ and atmospheric pressure.

2.2 Characterization of the polymer-based membrane

\subsubsection{Surface morphology analysis}

Scanning electron microscopy (SEM) was employed to visualize the surface morphology of low porosity membrane (LMP) and high porosity membrane (HPM) after depositing the polymer on the magnesium alloy surface. The average pore size and the total pore area were analyzed using CTAn program (Skyscan Company, Belgium).

2.2.2 Analysis of the thermal properties of the polymer-based membranes 
The thermal properties, including the transition temperatures such as the melting and crystallization temperatures and the crystallinity of the polymer-based membranes were determined by differential scanning calorimetry (DSC, TA Analysis, 2910 MDSC V4.4E). For the DSC measurement, the weight of the samples ranged from 5 to $10 \mathrm{mg}$ and the melting curves were recorded from $-20^{\circ} \mathrm{C}$ to $+80^{\circ} \mathrm{C}$ with a heating rate of $10^{\circ} \mathrm{C} / \mathrm{min}$. The melting point of PCL is approximately $60^{\circ} \mathrm{C}$ and therefore, 80 ${ }^{\circ} \mathrm{C}$ was chosen as the upper heating temperature in order to obtain complete melting of PCL membrane. Two cycles of heating and cooling were conducted, where the first cycle was used to eliminate the heat history of the polymer membrane [23]. All of the samples were firstly heated from $-20^{\circ} \mathrm{C}$ to $80^{\circ} \mathrm{C}$, and then maintained at $80^{\circ} \mathrm{C}$ for one minute to ensure the complete melting of the PCL crystals. The samples were subsequently quenched to $-20^{\circ} \mathrm{C}$ at the rate of $10^{\circ} \mathrm{C} / \mathrm{min}$ and then heated again from $20^{\circ} \mathrm{C}$ to $80^{\circ} \mathrm{C}$ at a rate of $10^{\circ} \mathrm{C} / \mathrm{min}$. The data was obtained from the second cycle.

2.3 Electrochemical corrosion analysis

An electrochemical test was conducted to evaluate the corrosion resistance of the polymer-deposited and untreated magnesium alloys. The samples were embedded in epoxy resin and the top surface was exposed for testing. The corrosion testing was conducted in a standard simulated body fluid (SBF) at a $\mathrm{pH}$ of 7.4 , and resistance was 
characterized by using potentiostat (VersaStat II EG\&G), and the corrosion medium was a standard simulated body fluid (SBF) at a $\mathrm{pH}$ of 7.4. The temperature was controlled at $37 \pm 0.5^{\circ} \mathrm{C}$ throughout testing. Prior to polarization, the samples were immersed in $500 \mathrm{ml}$ SBF for 15 minutes. The polarization scan started from $-220 \mathrm{mV}$ at a scan rate of $1 \mathrm{mV} / \mathrm{s}$, and the changes in the free corrosion potential $\left(\mathrm{E}_{\text {corr }}\right)$ were monitored as a function of time.

\subsection{Immersion test}

The immersion test was carried out at different time points to monitor the degradation and the release of magnesium ions of the polymer-deposited and untreated samples. Five of each of the polymer-deposited and untreated samples were individually immersed into sealable capsules containing $10 \mathrm{ml}$ SBF and then incubated at $37^{\circ} \mathrm{C}$ for a total of 2 months. The release of magnesium ions from the samples was measured at 9 different time points (i.e. 6 and 12 hours, and 1, 2, 4, 7, 14, 30, and 60 days) using inductively-coupled plasma mass spectrometry (ICPMS) (Optical Emission Spectrometer, Perkin Elmer, Optima 2100DV). The correlation between ion dissolution and time was subsequently established. In addition, the $\mathrm{pH}$ values of the samples were also measured, and the rate of corrosion was determined by measuring the weight lost from each of the samples. 
The magnesium hydroxide composites formed on the sample surface during corrosion were removed by immersing the samples into chromic acid $\left(200 \mathrm{~g} / 1 \mathrm{CrO}_{3}+\right.$ $10 \mathrm{~g} / 1 \mathrm{AgNO}_{3}$ ) for 5 minutes [24, 25]. Afterwards, the deposited samples were rinsed with running distilled water, and then dried under vacuum. The difference in weight before and after chromic acid immersion indicated the amount of magnesium hydroxide formation, and thus the amount of magnesium ions released from the sample.

\subsection{In-vitro studies}

\subsubsection{Cell viability test of the extracts from the immersion test}

The MTT assay was used to determine the cytotoxicity of the polymer-deposited samples to mammalian cells. The test was carried out by using an indirect method, where the immersion extracts collected from the immersion test were used for culturing cells. $7 \times 10^{4}$ cells $/ \mathrm{cm}^{2}$ SaOS-2 human osteoblasts were cultured in Dulbecco's Modified Eagle Medium (DMEM) (Invitrogen) supplemented with 10\% (v/v) fetal bovine serum (Biowest, France), antibiotics (100 U/ml of penicillin and $100 \mu \mathrm{g} / \mathrm{ml}$ of streptomycin), and $2 \mathrm{mM} \mathrm{L-glutamine}$ in a 96 -well tissue culture plate and incubated at $37^{\circ} \mathrm{C}$ in an atmosphere of $5 \% \mathrm{CO}_{2}$ and $95 \%$ air for one day. On the second day, the culture media in each well were replaced with immersion SBF 
extracts supplemented with $10 \%$ fetal bovine serum (FBS, Biowest, France), and incubated at $37^{\circ} \mathrm{C}$ in an atmosphere of $5 \% \mathrm{CO}_{2}$ and $95 \%$ for three days. $10 \mu \mathrm{L}$ of MTT solution [5mg thiazolyl blue tetrazolium bromide powder in $1 \mathrm{ml}$ phosphate buffered saline (PBS, OXOID Limited, England)] was then added into each well on the third day. The 96-well tissue culture plate containing MTT solution and cells were then incubated at $37^{\circ} \mathrm{C}$ in an atmosphere of $5 \% \mathrm{CO}_{2}$ and $95 \%$ air for a further three days. After incubation, $100 \mu 1$ of $10 \%$ sodium dodecyl sulphate (SDS, Sigma, USA) in $0.01 \mathrm{M}$ hydrochloric acid was added into each well and incubated at $37^{\circ} \mathrm{C}$ in an atmosphere of $5 \% \mathrm{CO}_{2}$ and $95 \%$ air for 18 hours. The absorbance was recorded by the multimode detector (Beckman Coulter DTX 880) at 570nm wavelength, with a reference wavelength of $640 \mathrm{~nm}$ to determine the cell viability in comparison to the control.

\subsubsection{Determination of cell compatibility of the polymer-coated magnesium alloy}

To evaluate the cyto-compatibility of the polymer-deposited magnesium alloys, standard cell culturing was applied to the coated and uncoated sample surfaces. Six of each of the coated and uncoated AZ91 magnesium alloy was fixed to the bottom of a 96-well tissue culture plate. A cell suspension consisting of $1.7 \times 10^{4} \mathrm{cells} / \mathrm{cm}^{2}$ enhanced Green Fluorescent Protein Osteoblasts (eGFPOB) was seeded onto the 
surface of the uncoated and coated sample surfaces, and into wells without any samples which served as a control for normal culturing conditions. Cells were grown in a volume of $100 \mu \mathrm{DMEM}$ medium and incubated at $37^{\circ} \mathrm{C}$ in an atmosphere of $5 \%$ $\mathrm{CO}_{2}$ and $95 \%$ air. Cell attachment and proliferation were examined after 1 and 3 days of culture, where triplicate samples were examined at each time point. Cells were allowed to reach confluence during the examination period. Cell morphology was observed by using a fluorescent microscope (Niko ECL IPSE 80i, Japan). The attached living eGFP-expressive osteoblasts were visualized using a 450-490 nm incident filter, and the fluorescence images were emitted at $510 \mathrm{~nm}$ and captured using a Sony DKS-ST5 digital camera.

\subsection{Mechanical testing}

Compression testing was used to determine and compare the bulk mechanical properties, including yield strength and Young's modulus, of the polymer-coated and uncoated samples during degradation.

The samples were immersed into SBF using the same protocol as described for the immersion test, and the mechanical properties were monitored at 9 different time intervals (i.e. 6 and 12 hours, and 1, 2, 4, 7, 14, 30, and 60 days). The testing speed was set at a rate equivalent to $0.45 \mathrm{~m} / \mathrm{m}$ min and a Material Testing System (MTS) 
858.02 Mini Bionix (USA) testing machine was used to conduct the compression testing.

2.7 In-vivo animal study

\subsubsection{Surgery}

The anaesthetic, surgical and post-operative care protocols were examined by and fulfilled the requirements of the University Ethics Committee of The University of Hong Kong, and the Licensing Office of the Department of Health of the Hong

\section{Kong Government.}

Three six-month old female New Zealand White rabbits from the Laboratory Animal Unit of The University of Hong Kong were used in this study. Their average weights were approximately $4.5-5.0 \mathrm{~kg}$ and the chosen operation site was the greater trochanter. Each rabbit was implanted with either of HPM-coated, LPM-coated or uncoated samples, where two samples were implanted into each rabbit. Both uncoated and HPM samples were implanted into the right greater trochanter while LPM samples were implanted into the left greater trochanter (as-shown in Figure 1). In order to monitor the in-vivo degradation of the coated and uncoated samples, serial time points of 1 week and 1 and 2 months were set.

Rabbits were anaesthetized with Ketamine $(35 \mathrm{mg} / \mathrm{kg})$, Xylazine $(5 \mathrm{mg} / \mathrm{kg})$ and 
Acepromazine $(1 \mathrm{mg} / \mathrm{kg})$ by subcutaneous administration. The operation sites of the rabbits were shaved. After anaesthesia, decortication was carried out. Two holes $3 \mathrm{~mm}$ in diameter were made at the greater trochanter through a minimal invasive approach. A hand driller was used to drill a hole $6 \mathrm{~mm}$ in depth. Subsequently, the magnesium rods were implanted into the prepared holes on either the left or right leg of the rabbits. The wound was then sutured layer by layer, and a proper dressing was applied over the incision. After the operation, all rabbits received subcutaneous injections of 1 $\mathrm{mg} / \mathrm{kg}$ terramycin (antibiotics) and $0.5 \mathrm{mg} / \mathrm{kg}$ ketoprofen. The rabbits were sacrificed 2 months post-operatively.

\subsubsection{Radiographic evaluation}

At each particular time point (i.e. 1 week, 1 and 2 months), x-ray radiography (Faxitron x-ray corporation) was conducted at the operation site so as to monitor the healing process immediately after the surgery and prior to sacrificing the rabbits.

\subsubsection{Analysis of the magnesium ion concentration in blood of implanted rabbits}

Blood was collected prior to, 1 week, 1 month, and 2 months after the operation to determine the magnesium ion concentrations in the blood. Blood was centrifuged at $1,339 \mathrm{~g}$ for $15 \mathrm{mins}$ at room temperature (2-5 Sartorius, Sigma, USA) and the sera 
were collected and stored at $4^{\circ} \mathrm{C}$ till analysis. Prior to analysis, the sera were diluted 10 times in double distilled water. The magnesium ion concentration was determined using inductively-coupled plasma mass spectrometry (ICPMS) (Optical Emission Spectrometer, Perkin Elmer, Optima 2100DV), and the concentrations of magnesium ions released from both treated and untreated samples were compared.

\subsubsection{Histological evaluation}

The bone samples with implants were harvested and fixed in $10 \%$ buffered formalin for 3 days. Subsequently, a standard tissue processing step was conducted to change the samples from an aqueous stage to an organic stage. A dehydrating process was performed using $70 \%$, followed by $95 \%$ then $100 \%$ ethanol. The samples were immersed in each of the solutions for 3 days. Xylene was subsequently used as a transition between ethanol and methyl-methacrylate, where the samples were immersed in xylene for 3 days. Finally, all the samples were embedded in methylmethacrylate (Technovit $9100 \mathrm{New}^{\circledR}$, Heraeus Kulzer, Hanau, Germany) as per manufacturer's instructions. Prior to cutting the samples, the whole embedded samples were scanned in a micro-computed tomography device (SKYSCAN 1076, Skyscan Company) to view the extent of corrosion of the samples. After scanning, 2D planes were reconstructed using the NRecon (Skyscan Company) and the 3D models 
were generated by CTVol (Skyscan Company). The residual implant volume was then analyzed using CTAn program (Skyscan Company) which is used to examine microCT datasets for morphometry and densitometry, as well as new bone growth. After analyzing by micro-CT, the embedded samples were then cut into sections with a thickness of $200 \mu \mathrm{m}$ and then micro-grounded down to $50-70 \mu \mathrm{m}$ thickness. The sectioned samples were stained with gimesa (MERCK, Germany) stain. The morphological and histological analyses were performed and viewed under a light microscope to observe for any bone on-growth and integration with the host tissue.

\section{Results}

\subsection{Characterization of the polymer membrane}

\subsubsection{Surface morphology analysis}

Figure 2 shows the surface morphologies of the polymer-deposited samples under scanning electron microscopy (SEM). The total pore area of the LPM sample was found to be approximately $236 \mu \mathrm{m}^{2}$ in which most of the pores were between 0.8 $\mu \mathrm{m}$ and $1.6 \mu \mathrm{m}$ in size. The average pore size was $0.302 \mu \mathrm{m}$, and the porosity of the LPM sample was $18.2 \%$. On the other hand, the total pore area of the HPM sample was approximately $572.1 \mu \mathrm{m}^{2}$, with the pore size ranging between $3.2 \mu \mathrm{m}$ and $6.4 \mu \mathrm{m}$. The average pore size $0.995 \mu \mathrm{m}$, and the porosity of the HPM sample was $44.1 \%$ (as 
shown in Figure 3).

3.1.2 Analysis of the thermal properties of the polymer-based membranes

Differential scanning calorimetry (DSC) was used to study the thermal properties of the polymer membranes. Figure 4 shows the heating and cooling thermograms of different PCL membranes, respectively. The melting temperature $\left(\mathrm{T}_{\mathrm{m}}\right)$ and the change of melting of heat $\left(\triangle \mathrm{H}_{\mathrm{m}}\right)$ were obtained from the heating thermograms while the crystallization temperature $\left(\mathrm{T}_{\mathrm{c}}\right)$ was identified from the cooling thermograms. The crystallinity degree $\mathrm{X}_{\mathrm{c}} \%$ of the polymer membrane could be determined by using the reference of $136 \mathrm{~J} / \mathrm{g}$ for crystalline polycaprolactone [26, 27]. Pure PCL had the highest melting temperature of $61.24^{\circ} \mathrm{C}$ and the lowest crystallization temperature of $18.15^{\circ} \mathrm{C}$ as compared to the polymer-coated samples. The melting temperatures were decreased from pure PCL towards HMP in which HPM was having the melting temperature of $56.2^{\circ} \mathrm{C}$ whereas the crystallization temperatures were increased from pure PCL to HPM where it had the crystallization temperature of $29.03^{\circ} \mathrm{C}$. The highest crystallinity was found on the HPM of $41.3 \%$ whereas the lowest crystallinity was found on the PCL only of $35.9 \%$. LPM had approximately $2 \%$ lower crystallinity as compared to the HPM. The data obtained from the DSC thermograms are summarized in Table 1. 


\subsection{Electrochemical measurement}

The electrochemical polarization curves of the PCL samples are shown in Figure 5. The corrosion potential (Ecorr) showed that the polymer-coated magnesium alloys shifted the open circuit potential to a more positive potential. The Ecorr, with reference to the AZ91 uncoated magnesium alloy, increased by $1444 \mathrm{mV}$ in LPM samples and $1114 \mathrm{mV}$ in HPM samples. At the same time, the values of the corrosion current (Icorr) of the polymer-coated samples, especially LPM sample, were lower than that of the uncoated sample. Therefore, both the Ecorr and Icorr showed that the PCL-coated samples were able to enhance the corrosion resistance of magnesium alloy.

\subsection{Immersion test}

Figures 6 and 7 show the concentration of the magnesium ions released and the $\mathrm{pH}$ values of the polymer-coated and uncoated magnesium alloys, respectively. The magnesium ion concentrations as determined by inductively coupled plasma mass spectrometry (ICPMS) of the uncoated samples was found to increase from approximately 19 ppm after 6 hours of immersion, to 1,360 ppm after 60 days of immersion, while the coated samples had a very slow release rate by comparison. The magnesium ion concentrations that were detected between 6 hours and 60 days of immersion for the LPM and HPM samples ranged between $2.6 \mathrm{ppm}$ to $238.6 \mathrm{ppm}$ and 
from $2.4 \mathrm{ppm}$ to $433.4 \mathrm{ppm}$, respectively. The results revealed that the amount of magnesium leached from all the coated samples were significantly $(p<0.05)$ reduced compared to the uncoated sample. The $\mathrm{pH}$ range of LPM and HPM samples was found to be between 7.17 to 7.62 , and 7.19 to 7.86 , respectively, after 2 months of immersion, while the uncoated sample had the $\mathrm{pH}$ values ranging between 7.52 and 8.20 .

Figure 8 shows the degradation rate of the PCL-coated and uncoated samples in terms of the amount of weight lost from the samples. The total weight lost from the uncoated sample was approximately $17 \mathrm{mg}$ after 2 months of immersion, however, for the polymer-coated samples, the total weight lost from the LPM and HPM samples after 2 months were $3.59 \mathrm{mg}$ and $6.22 \mathrm{mg}$, respectively.

\subsection{In-vitro studies}

\subsubsection{Cell viability test of the extracts from the immersion test}

Figure 9 shows the SaOS-2 human cell viability which grown in the extracts from the immersion test, as determined by the MTT assay. All the extracts of the polymer-coated samples (LPM and HPM) were well tolerated by the osteoblasts with the cell viability ranging from $130 \%$ to $80 \%$ until day 60 , while the uncoated samples ranged from $130 \%$ to $20 \%$. A sudden drop in the cell viability of the uncoated samples 
was observed after day 4 , whereas the cell viability of the polymer-coated samples remained at approximately $100 \%$. The correlation between cell viability and the amount of magnesium ions released is shown in Figures $10 \mathrm{a}$ and $10 \mathrm{~b}$. The highest amount of magnesium ions released from the HPM sample at day 60 was 443 ppm with a cell viability of $80 \%$, whereas the highest amount of magnesium ions released from the LPM sample was 240 ppm with a cell viability of approximately $96 \%$. However, for the uncoated samples, the amount of magnesium ions released at day 60 was $1,360 \mathrm{ppm}$ which was associated with a cell viability of $25 \%$.

3.4.2 Determination of cell attachment and growth of the polymer-coated magnesium alloy

Figure 11 shows that viable cells were observed on the uncoated and polymercoated samples after 1 and 3 days of cell culturing. On day 1 focal adhesion and cells spreading were observed on the polymer-coated samples (Figure 11a), while no cell attachment was observed on the uncoated sample. After 3 days of cell culture (Figure $11 \mathrm{~b}$ ), the osteoblasts exhibited good cell spreading and had almost grown to $100 \%$ confluency on the polymer-coated samples, in contrast to the uncoated sample which had no cell growth. 


\subsection{Mechanical characterization}

Figure 12 shows the results of the compression test. The compressive strengths of both coated and uncoated samples were found to be similar before immersion (i.e. time point 0 ). Subsequently, the strength of the uncoated samples decreased as the immersion period increased, while the strength of the polymer-coated samples kept constant between the 6 hours and 60 days time points. The compressive strengths of LPM and HPM samples remained at approximately 170MPa after 60 days of immersion, however, that of the uncoated sample has dropped to $111 \mathrm{MPa}$. Therefore, the polymer-coated samples were able to maintain a constant compressive strength for a period of time.

\subsection{In-vivo animal study}

\subsubsection{Radiographic evaluation}

Figure 13 shows the radiographs of the rabbit greater trochanter after 1 week, 1 and 2 months post-operation. No gas bubbles were observed after implantation, and all the implants were intact throughout the whole implantation period. However, the radiographs of the whole implants were not clear under x-ray radiography, therefore other evaluation method including the Micro-computed tomography analysis was adopted to observe the degradation rate of the implant. 


\subsubsection{Micro-computed tomography analysis}

The in-vivo corrosion morphology of the implant in the greater trochanter in the New Zealand White rabbits was studied using micro-computed tomography. Figure 14 shows the cross sections and 3D models of the implants. The whole implant could be visualized after conducting the reconstructions. Corrosion (red arrows in Figures $14 \mathrm{~d}$, f, $g$ and i) was observed on both uncoated and HPM but not on LPM samples. Moreover, all the samples showed direct contact with the newly formed bone, where the PCL membrane was clearly seen on the LPM and HPM samples (yellow arrows in Figures $14 \mathrm{e}$ and $\mathrm{f}$ ). Figure 15 shows the 3D models of the newly formed bone on both coated and uncoated implants, and Table 2 shows the values of the newly formed bone volume around the implants and the volume reduction of the implants. The uncoated magnesium alloy showed the least volume of new bone growth of $1.36 \mathrm{~mm}^{3}$ and the largest volume reduction of $0.33 \%$ after 2 months of implantation (Figure 15a). Among the polymer sprayed samples, HPM had also corroded, however, had a smaller implant volume reduction $(0.05 \%)$ and more bone formation $\left(5.17 \mathrm{~mm}^{3}\right)$ than the uncoated sample. The LMP sample had the greatest amount of new bone formation of $10.79 \mathrm{~mm}^{3}$ and did not have any implant volume reduction. 


\subsubsection{Serum magnesium measurements}

Figure 16 shows the changes in the serum magnesium levels of all the implants after 2 months post-operation. The serum magnesium levels of all the rabbits were noted to fluctuate from approximately $13 \mathrm{ppm}$ to $19 \mathrm{ppm}$. No trend could be determined from the results.

\subsubsection{Histological evaluation}

Figure 17 shows the tissue response to both polymer-coated and uncoated magnesium alloy after 2 months of implantation, where new bone tissue (black arrows) was observed to form around the implant. All the samples showed direct contact with the newly formed bone. Osteoblasts, which are responsible for new bone formation, were also observed around the implants (green arrows). More bone was formed around the polymer-coated implants in comparison to the un-coated sample.

\section{Discussion}

The use of magnesium alloys as biodegradable materials was first investigated during the first half of the last century [28, 29]. The major obstacles of applying magnesium alloys in clinical use are its rapid degradation rate and the release of hydrogen gas upon degradation. Hence, different modifications of magnesium alloys 
have been conducted, of which one of the approaches is surface modification $[12,17$, 18, 30-32]. By conducting a suitable surface modification, the corrosion resistance properties of magnesium alloys may be enhanced.

In this study, we constructed degradable polymeric membranes with controllable porosity and deposited these onto the magnesium alloys. The pore formation was mainly due to the process of phase separation [33, 34] in which the solvent evaporation in the polymer solution acted as a driving force for phase separation since the polymer solution became thermodynamically unstable during solvent evaporation. This resulted in the formation of either a polymer-rich or polymer-poor phase [35-37], where the polymer-rich phase would be solidified, whereas the polymer-poor phase led to pore formation. Moreover, the size of the pores was related to the concentration of the polymer solution, where a more concentrated polymer solution resulted in smaller pores due to the presence of less polymer-poor phase [38, 39], and this explains why larger pores were observed on the HPM as compared to the LPM. In addition, the polymer membrane was deposited layer-by-layer with smaller pores in the inner layer which was mainly due to the amount of polymer present in each layer. We assumed that part of the outer layer of polymer would merge into the pores of the inner layer which would result in the pores being filled up, however, as it is impossible to completely fill these, smaller pores were therefore observed in the inner 
layer. As a result of this, lower amounts of polymer were present in the outer layer which led to the formation of larger pores in the outer layer. Further studies to verify this are currently in progress.

The compressive strengths of both the coated and uncoated samples at the 0 hour time point were found to be similar since the polymer membrane did not affect the bulk mechanical properties of the magnesium alloy. Whilst the compressive strength of the uncoated sample dropped significantly due to corrosion and magnesium ion release during the early time points, the rate of decrease in the compressive strength was reduced at later time points due to magnesium hydroxide formation [40]. However, the compressive strengths of the polymer-coated samples remained at least $60 \mathrm{MPa}$ higher than the uncoated samples after two months of immersion, which was largely due to the slower corrosion rate of the implant. This is a critical factor to consider for the application of polymer-based membranes in orthopaedic implants. The mechanical integrity of an orthopaedic implant is very important since it is used to fix fractured bones, therefore, the implant must provide enough mechanical support to the bone throughout the healing process. Since the strength of an uncoated implant decreased more than $50 \%$ in two months due to corrosion, the slower rate of corrosion of the polymer-coated implants, which were still maintained at above $70 \%$, would thus suit the application of orthopaedic implants as the strength of the implant is 
maintained within the first two months which would allow for a longer period of time for bone fractures to heal. However, further long-term studies are needed to confirm this.

From the radiographs, no gas bubbles were observed throughout the entire experimental period for both polymer-coated and uncoated samples, which was different from other studies $[5,12]$. Witte et al. [12] reported that the implantation of AZ91 magnesium alloy into guinea pig femora intramedullary resulted in gas bubbles appearing within one week of implantation and subsequently disappearing after two to three weeks, whereas in another study, the appearance of gas bubbles occurred during the first month [5]. The difference between this study and Witte's study may be explained by a number of reasons including the different animal model used, the size of the implant, and the implantation site. Although we used the same type of AZ91 magnesium alloy, the sample that Witte et al. (2005) used had a surface-to-volume ratio approximately 1.65 times larger than the one used in our study, which would have resulted in a large surface area exposed to the body, thereby increasing the amount of corrosion of the implant. This could have resulted in a hydrogen gas release rate that was faster than the absorption rate, which may explain why hydrogen gas was observed during the first three weeks after implantation. Over time, the corrosion rate would have slowed down because of the formation of magnesium 
hydroxide [12], and thus the gas would have been absorbed afterwards, which accounts for the disappearance of the hydrogen gas bubbles after two to three weeks [5].

In order to visualize the corrosion morphology and quantify the in-vivo corrosion rate, micro-computed tomography was employed. Under in-vivo conditions, slight corrosion occurred on HPM but not on the LPM, which correlated with the in-vitro data. Since increased numbers of pores, and larger pore size were found on the HPM, this allowed more body fluid to pass through and make contact, therefore increasing the amounts of corrosion of the HPM in comparison to the LPM. Nonetheless the uncoated implant still corroded the fastest out of the three types of samples. This indicated that the polymer membrane was able to reduce the release of magnesium ions, thereby controlling the degradation rate of magnesium alloy in the in-vivo environment.

Bone formation was studied and quantified using micro-computed tomography. The newly formed bone was found around the implants of both coated and uncoated samples and there were no adverse effects were found after implantation, which proved their biocompatibility. Although corrosion occurred on uncoated and HPM samples, bone formation was still observed around those implants, which concur with others' findings [5,7]. However, upon comparison of the amount of new bone 
formation, it was found that the uncoated sample had the least amount of new bone formation and the polymer-coated samples had the new bone volume in descending order of LPM > HPM. Higher amounts of bone formation around the polymer-coated samples as compared to the uncoated samples may be due to several reasons. One reason for this may be attributed to a reduced rate of corrosion, as the polymer coating decreased the amount of direct contact with the body. In addition, large amounts of magnesium ion release during corrosion of the uncoated sample possibly inactivated new bone formation [41], thereby resulting in less new bone formation around the uncoated sample when compared to the polymer-coated samples. The high levels of new bone formation found on the LPM sample may be explained by the release of low levels of magnesium ions, which has been reported to enhance osteoblastic activity and thus generate a stimulatory effect on the growth of new bone tissue [1, 42], and also correlated with the MTT data in this study. Hence, LPM-coated samples may have induced more new bone formation due to the release of low levels of magnesium ions.

Histological analysis revealed an area of bone formation around the implants and although corrosion was found on uncoated and HPM samples in the histological staining, which was confirmed with micro-CT analysis, there was an absence of inflammation and necrosis, which suggested that there were no toxic effects in the 
surrounding tissues. This was a good indication that the coated sample would be safe for in-vivo use, considering that once the polymer membrane degraded, the un-coated magnesium alloy would also degrade and not induce adverse effects into the localized tissues. This correlated with the serum magnesium measurements where no significant differences were observed between the serum magnesium levels after implantation for either the coated or uncoated samples, which most likely due to homeostatic regulation by the kidney $[12,43]$. The detected serum magnesium ion levels were below $20 \mathrm{ppm}$ and were within the normal range of physiological magnesium levels [43-46]. Correlating the observed serum magnesium levels with the MTT assay data, a toxic effect occurred only if the magnesium ion concentration exceeded $150 \mathrm{ppm}$, which indicated that there should be no toxicity problems occurring in-vivo. Taking this data together, the polymer-coated samples reduces the rate of magnesium ion release and allows for the homeostatic maintenance of physiological magnesium levels. More importantly, the data indicates that after the polymer-coating is degraded, thus leaving behind the uncoated implant, the release of magnesium ions from this uncoated implant does not induce toxic levels of magnesium. Further long-term in-vivo studies, which continue until complete degradation of the implant, are needed to verify this. 


\subsection{Conclusion}

In summary, this study demonstrated the effectiveness of applying a porosity controllable biodegradable polymer membrane on a magnesium alloy. The addition of a polymer-coating on the implant was shown to reduce the corrosion rate of the implant. This was mainly related to the pore size of the membrane, which may be altered during synthesis to suit potential applications. In addition to reducing the corrosion rate of the magnesium alloy, the polymer-coated samples also aided in retaining the mechanical strength of the implant in contrast to uncoated samples during the immersion test. This is a great advantage for the application of polymercoated implants for orthopaedic procedures as the slower release rate of magnesium ions and strength of the polymer-coated implants allows for sufficient time for bone healing and also promotes new bone growth. Our study also indicated good cell biocompatibility with no observed inflammation or necrosis. Additionally, the serum magnesium levels after implantation were retained within a normal physiological range. This was also observed for the uncoated samples, which indicated that after degradation of the polymer coating from the implant, further corrosion of the implant would not result in cell toxicity. Further studies are needed to improve the membrane's adhesion properties to the implant and additional long-term in-vivo studies are required to further validate the use of polymer-coated implants for 
orthopaedic implants.

\section{Acknowledgement}

This study was financially supported by the Hong Kong Research Grant Council

Competitive Earmarked Research Grant (\#718507) and HKU University Research

Council Seeding Fund.

\section{References}

1. Staiger MP, Pietak AM, Huadmai J, Dias G. Magnesium and its alloys as orthopedic biomaterials: A review. Biomaterials 2006;27(9):1728-1734.

2. Niinomi M. Recent metallic materials for biomedical applications. Metall Mater Trans A 2002;33:447-486.

3. Denkena B., Witte F., Podolsky C., Lucas A. Degradable implants made of magnesium alloys. Proc of 5th euspen International Conference-MontpellierFrance 2005.

4. Witte F, Fischer J, Nellesen J, Crostack H-A, Kaese V, Pisch A, et al. In vitro and in vivo corrosion measurements of magnesium alloys. Biomaterials 2006;27(7):1013-1018.

5. Li Z, Gu X, Lou S, Zheng Y. The development of binary Mg-Ca alloys for use as biodegradable materials within bone. Biomaterials 2008;29(10):1329-1344.

6. Xu L, Pan F, Yu G, Yang L, Zhang E, Yang K. In vitro and in vivo evaluation of the surface bioactivity of a calcium phosphate coated magnesium alloy. Biomaterials 2009;30(8):1512-1523.

7. Xu L, Yu G, Zhang E, Pan F, Yang K. In vivo corrosion behavior of Mg-Mn-Zn alloy for bone implant application. J Biomed Mater Res 2007;83A:703-711.

8. Gray JE, Luan B. Protective coatings on magnesium and its alloys -- a critical review. J Alloys Compd 2002;336(1-2):88-113.

9. Yamamoto A, Watanabe A, Sugahara K, Tsubakino H, Fukumoto S. Improvement of corrosion resistance of magnesium alloys by vapor deposition. Scr Mater 2001;44(7):1039-1042. 
10. Troitskskii VV, DN T. The resorbing metallic alloy 'OSteosinthezit' as material for fastening broken bone. Khirurgiia 1944;8:60-63.

11. Kaesel V.T., Bach P.T., Haferkamp H., Witte F., Windhagen H., Apporach to control the corrosion of magnesium by alloying. Proceedings of the sixth international conference magnesium alloys and their applications 2004;New York: Wiley-Vch:534539.

12. Witte F, Kaese V, Haferkamp H, Switzer E, Meyer-Lindenberg A, Wirth CJ, et al. In vivo corrosion of four magnesium alloys and the associated bone response.

Biomaterials 2005;26:3557-3563.

13. Song G, StJohn D. The effect of zirconium grain refinement on the corrosion behaviour of magnesium-rare earth alloy MEZ. J Light Met 2002;2(1):1-16.

14. Fan $\mathrm{Y}, \mathrm{Wu} \mathrm{G}, \mathrm{Zhai} \mathrm{C}$. Influence of cerium on the microstructure, mechanical properties and corrosion resistance of magnesium alloy. Mater Sci Eng A 2006;433(12):208-215.

15. Zhang S, Li J, Song Y, Zhao C, Zhang X, Xie C, et al. In vitro degradation, hemolysis and MC3T3-E1 cell adhesion of biodegradable $\mathrm{Mg}-\mathrm{Zn}$ alloy. Mater Sci Eng C 2009;29(6):1907-1912.

16. Zberg B, Uggowitzer PJ, Loffler JF. MgZnCa glasses without clinically observable hydrogen evolution for biodegradable implants. Nat Mater 2009;8:887891.

17. Chen F, Zhou H, Yao B, Qin Z, Zhang Q. Corrosion resistance property of the ceramic coating obtained through microarc oxidation on the AZ31 magnesium alloy surfaces. Surf Coating Tech 2007;201(9-11):4905-4908.

18. Wang YQ, Wu K, Zheng MY. Effects of reinforcement phases in magnesium matrix composites on microarc discharge behavior and characteristics of microarc oxidation coatings. Surf Coating Tech 2006;201(1-2):353-360.

19. Hoche H, Scheerer H, Probst D, Broszeit E, Berger C. Plasma anodisation as an environmental harmless method for the corrosion protection of magnesium alloys. Surf Coating Tech 2003;174-175:1002-1007.

20. Shi P, Ng WF, Wong MH, Cheng FT. Improvement of corrosion resistance of pure magnesium in Hanks' solution by microarc oxidation with sol-gel TiO2 sealing. $\mathrm{J}$ Alloys Compd 2009;469(1-2):286-292.

21. Wang X, Zeng X, Wu G, Yao S, Lai Y. Effects of tantalum ion implantation on the corrosion behavior of AZ31 magnesium alloys. J Alloys Compd 2007;437(1-2):87-92. 22. Zhu XM, Yang HG, Lei MK. Corrosion resistance of Al ion implanted AZ31 magnesium alloy at elevated temperature. Surf Coating Tech 2007;201(15):66636666.

23. Xu X, Li B, Lu H, Zhang Z, Wang H. The interface structure of nano-SiO2/PA66 
composites and its influence on material's mechanical and thermal properties. Appl Surf Sci 2007;254(5):1456-1462.

24. Witte F, Feyerabend F, Maier P, Fischer J, Stormer M, Blawert C, et al.

Biodegradable magnesium-hydroxyapatite metal matrix composites. Biomaterials 2007;28(13):2163-2174.

25. Liu C, Xin Y, Tang G, Chu PK. Influence of heat treatment on degradation behavior of bio-degradable die-cast AZ63 magnesium alloy in simulated body fluid. Mater Sci Eng A 2007;456(1-2):350-357.

26. Taddei P, Tinti A, Reggiani M, Fagnano C. In vitro mineralization of bioresorbable poly([epsilon]-caprolactone)/apatite composites for bone tissue engineering: a vibrational and thermal investigation. J Mol Struct 2005;744-747:135143.

27. Crescenzi V., Manzini G., Calzolari G., Borri C., Thermodynamics of fusion of poly-b-propiolactone and poly-e-caprolactone. Comparative analysis of the melting of aliphatic polylactone and polyester chains. Eur Polym J 1972;8:449-463.

28. McBride E. Absorbable metal in bone surgery. J Am Med Assoc 1938;111:24642467.

29. Verbrugge J. Le Material Metallique Resorbable En Chirurgie Osseuse. Presse Med 1934;23:460-465.

30. Bakkar A, Neubert V. Improving corrosion resistance of magnesium-based alloys by surface modification with hydrogen by electrochemical ion reduction (EIR) and by plasma immersion ion implantation (PIII). Corr Sci 2005;47(5):1211-1225.

31. Li GY, Lian JS, Niu LY, Jiang ZH, Jiang Q. Growth of zinc phosphate coatings on AZ91D magnesium alloy. Surf Coating Tech 2006;201(3-4):1814-1820.

32. Zhao M, Wu S, An P, Luo J, Fukuda Y, Nakae H. Microstructure and corrosion resistance of a chromium-free multi-elements complex coating on AZ91D magnesium alloy. Mater Chem Phys 2006;99(1):54-60.

33. McCann JT, Marquez M, Xia Y. Highly Porous Fibres by Electrospinning into a Cryogenic Liquid. J Am Chem Soc 2006;128:1436-1437.

34. Wu YQ, RL C. Controllable porous polymer particles generated by electrospraying. J Colloid Interface Sci 2007;310:529-535.

35. Bognitzki M, Czado W, Frese T, Schaper A, Hellwig M, Steinhart M, et al. Nanostructured Fibres via Electrospinning. Adv Mater 2001;13:70-72.

36. Dayal P, Liu J, Kumar S, Kyu T. Experimental and Theoretical Investigations of Porous Structure Formation in Electrospun Fibers. Macromolecules 2007;40:76897694.

37. Megelski S, Stephens JS, Chase DB, Rabolt JF. Micro- and Nanostructured Surface Morphology on Electrospun Polymer Fibers. Macromolecules 2002;35:8456- 
8466.

38. Liu J, Kumar S. Microscopic polymer cups by electrospinning. Polymer 2005;46:3211-3214.

39. Zheng J, He A, Li J, Xu J, CC H. Studies on the controlled morphology and wettability of polystyrene surfaces by electrospinning or electrospraying. Polymer 2006;47:7095-7102.

40. Song GL. Recent Progress in Corrosion and Protection of Magnesium Alloys. Adv Eng Mater 2005;7:563-586.

41. Serre CM, Papillard M, Chavassieux P, Voegel JC, Boivin G. Influence of magnesium substitution on a collagen-apatite biomaterial on the production of a calcifying matrix by human osteoblasts. J Biomed Mater Res 1998;42(4):626-633. 42. H. Zreiqat, C. R. Howlett, A. Zannettino, P. Evans, G. Schulze-Tanzil, C. Knabe, et al. Mechanisms of magnesium-stimulated adhesion of osteoblastic cells to commonly used orthopaedic implants. J Biomed Mater Res 2002;62(2):175-184.

43. Vormann J. Magnesium: nutrition and metabolism. Mol Aspects Med 2003;24:27-37.

44. Saris N-EL, Mervaala E, Karppanen H, Khawaja JA, Lewenstam A. Magnesium: An update on physiological, clinical and analytical aspects. Clin Chim Acta 2000;294(1-2):1-26.

45. Pybus J. Determination of calcium and magnesium in serum and urine by atomic absorption spectrophotometry. Clin Chim Acta 1968;23(2):309-317.

46. Rettig R, Virtanen S. Composition of corrosion layers on a magnesium rare-earth alloy in simulated body fluids. J Biomed Mater Res A 2009;88(2):359-369.

Figure captions 
Figure 1 Uncoated and PCL-coated sample rods implantation in greater trochanter of New Zealand White rabbit for 2 months. (a) Uncoated, (b) LPM and (c) HPM

Figure 2 Surface morphology of the polymer membranes under scanning electron microscopy (SEM). (a)

LPM, (b) HPM

Figure 3a Characterization of the pores formed on the LPM using CTAn software

Figure 3b Characterization of the pores formed on the HPM using CTAn software

Figure 4 Heating and cooling scans of DSC thermograms of different PCL membranes. $T_{m}$ represents the melting temperature while $T_{c}$ represents the crystallization temperature

Figure 5 Potentiodynamic polarization curves of PCL coated and uncoated magnesium alloys which was obtained from the electrochemical measurement. The polarization scan started from $-220 \mathrm{mV}$ at a scan rate of $1 \mathrm{mV} / \mathrm{s}$ and the changes in the free corrosion potential $\left(E_{\text {corr }}\right)$ were monitored as a function of time Figure 6 Magnesium ions released from PCL-coated and uncoated AZ91 magnesium alloy over time as measured by inductively coupled plasma mass spectrometry (ICPMS). All the values of both the LPM and HPM samples were found to be significantly different $(p<0.05)$ when compared with the uncoated sample

Figure $7 \mathrm{pH}$ values of PCL-coated and uncoated AZ91 magnesium alloy over time. All the values of both the LPM and HPM samples were found to be significantly different $(p<0.05)$ when compared with the uncoated sample

Figure 8 Total weight lost from PCL-coated and uncoated AZ91 magnesium over time 
Figure 9 Cell viability of PCL-coated and uncoated AZ91 magnesium alloy over time as derived from the absorbance reading at 570nm wavelength using the MTT assay. The reference wavelength of $640 \mathrm{~nm}$ was used to determine the cell viability in comparison to the control

Figure 10 Correlation between cell viability and the magnesium ion concentration of PCL-coated and uncoated AZ91 magnesium alloy. (a) PCL-coated, (b) Uncoated samples

Figure 11 Microscopic views of GFP mouse osteoblasts cultured on PCL-coated and uncoated AZ91 magnesium alloy after 1 and 3 days. (a) 1 day; (b) 3 days. 5,000 GFPOB were cultured on the coated and uncoated samples for 1 and 3 days so as to evaluate the cyto-compatibility of the polymer-coated magnesium alloys.

Figure 12 Compressive strength of PCL-coated and uncoated AZ91 magnesium alloy over time. The compression test was conducted by using the Material Testing System (MTS) with the testing speed $0.45 \mathrm{~m} / \mathrm{m} \cdot \min$

Figure 13 Radiographs of PCL-coated and uncoated AZ91 magnesium alloy after 1 week, 1 and 2 months post-operation. (a to c) uncoated, LPM, and HPM after 1 week post-operation, respectively; (d to f) uncoated, LPM and HPM after 1 month post-operation, respectively; ( $\mathrm{g}$ to i) uncoated, LPM and HPM after 2 months post-operation, respectively

Figure 14 Micro-CT reconstruction images of the greater trochanter containing coated and uncoated sample. (a to c) transverse view; ( $d$ to f) coronal view and ( $g$ to i) 3D view of the uncoated, LPM and HPM samples. The corrosion condition of the samples can be scanned and viewed in a micro-computed 
tomography device

Figure 15 Micro-CT 3D reconstruction models of newly formed bone (white in color) on both coated and uncoated implants. (a) Uncoated, (b) LPM and (c) HPM

Figure 16 Changes in serum magnesium levels before and after implantation. The serum was collected by centrifugation at 1,339 $\mathrm{g}$ for 15 mins at room temperature. The magnesium ion concentration was determined by inductively-coupled plasma mass spectrometry (ICPMS)

Figure 17 Histological photographs of gimesa stained of the bone tissue formed around the implant after 2 months' implantation in the greater trochanter where arrows represent the newly formed bone and circles represent the presence of osteoblasts. (a) Uncoated, (b) LPM and (c) HPM

Figure 1 

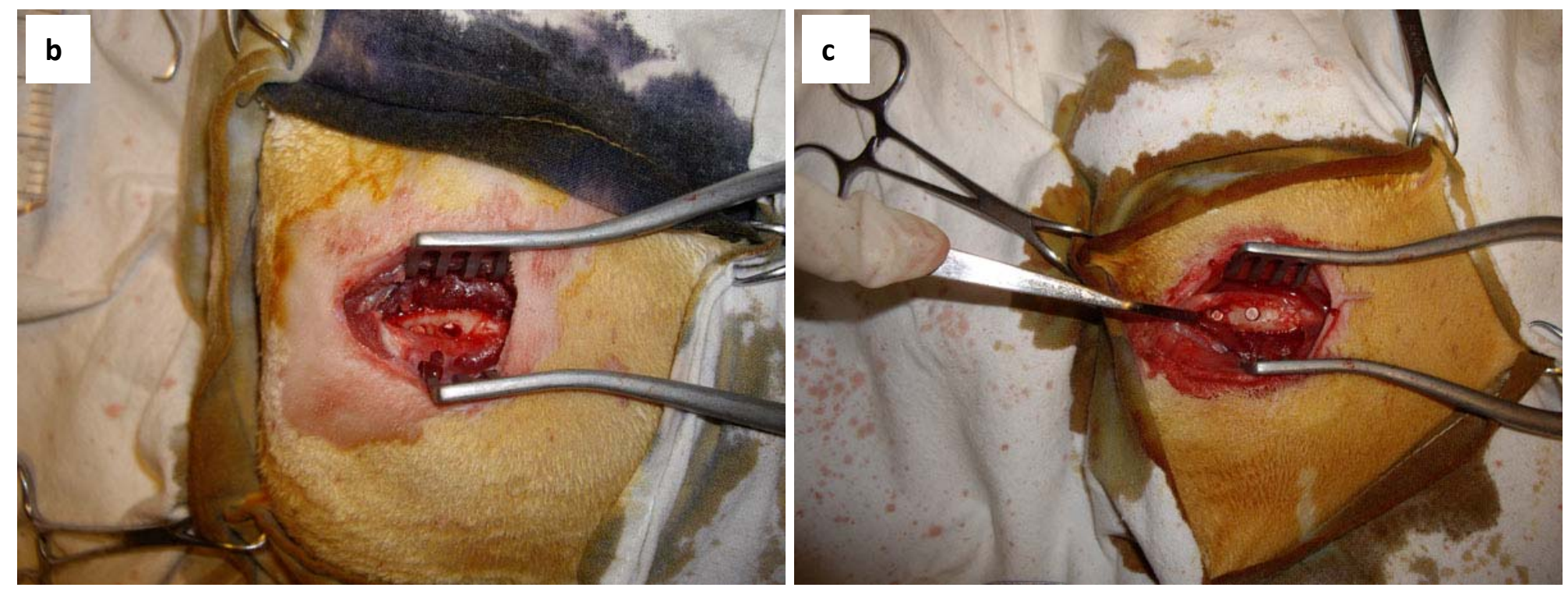
Figure 2

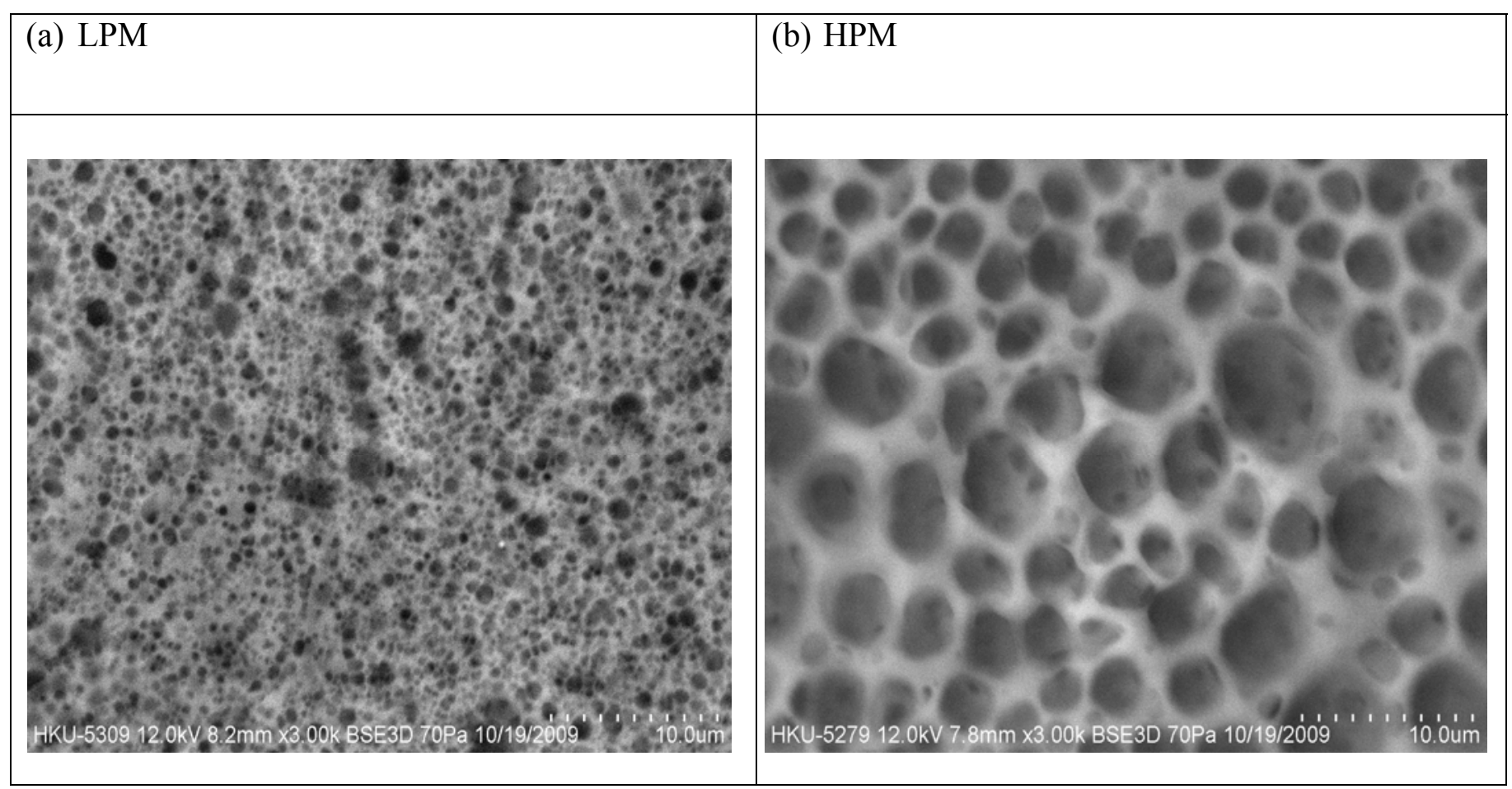


Figure 3a

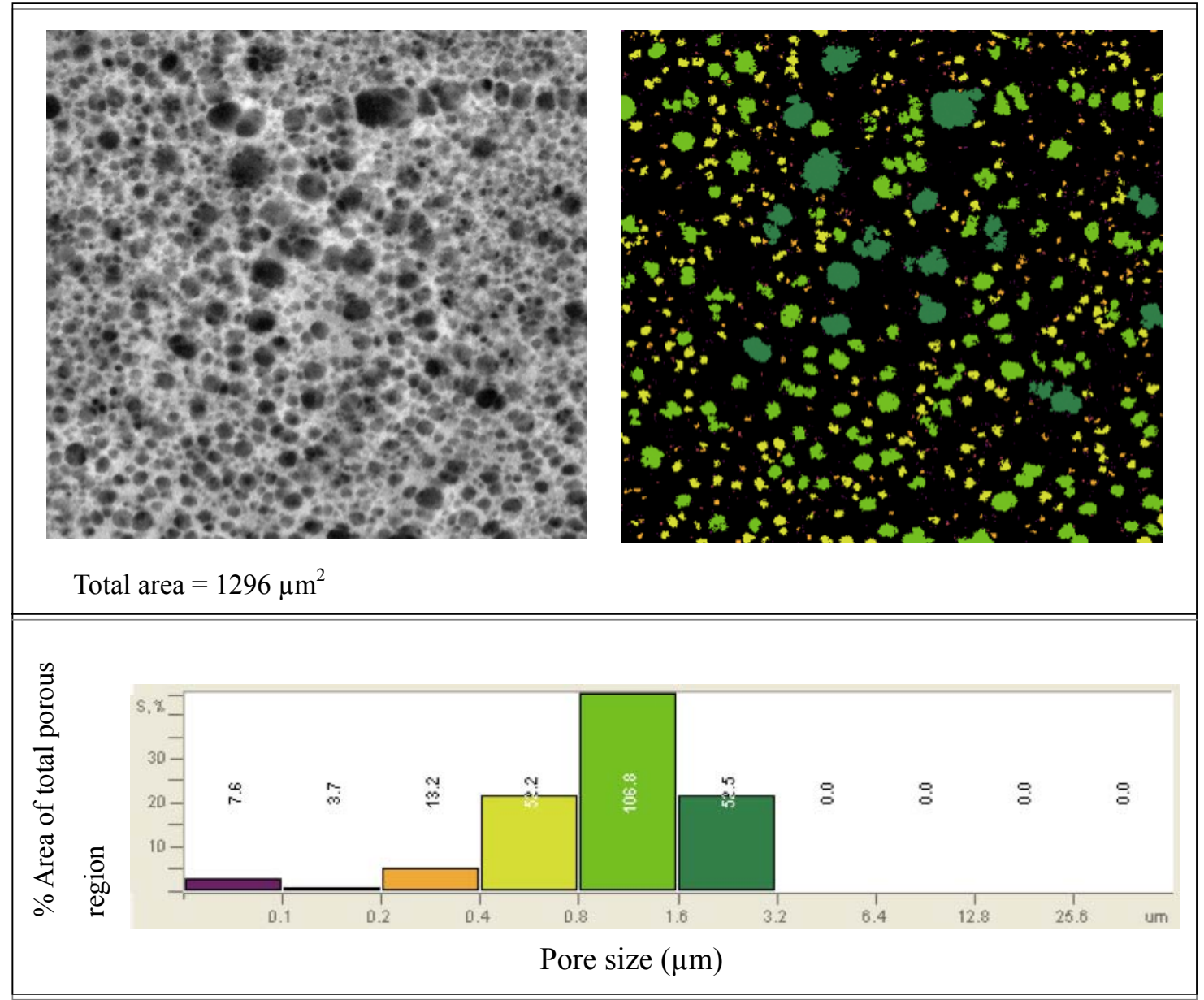


Figure $3 b$

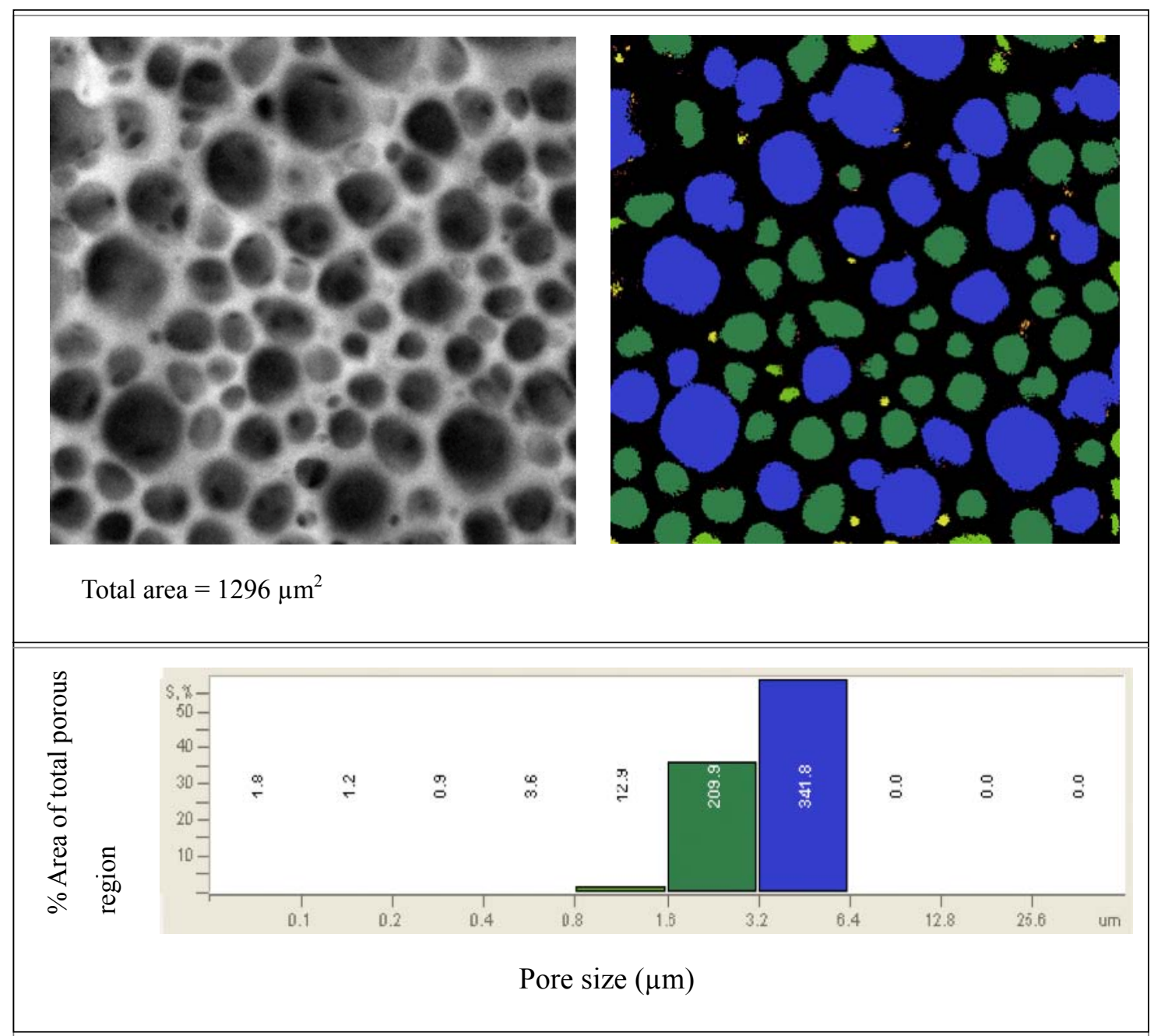


Figure 4

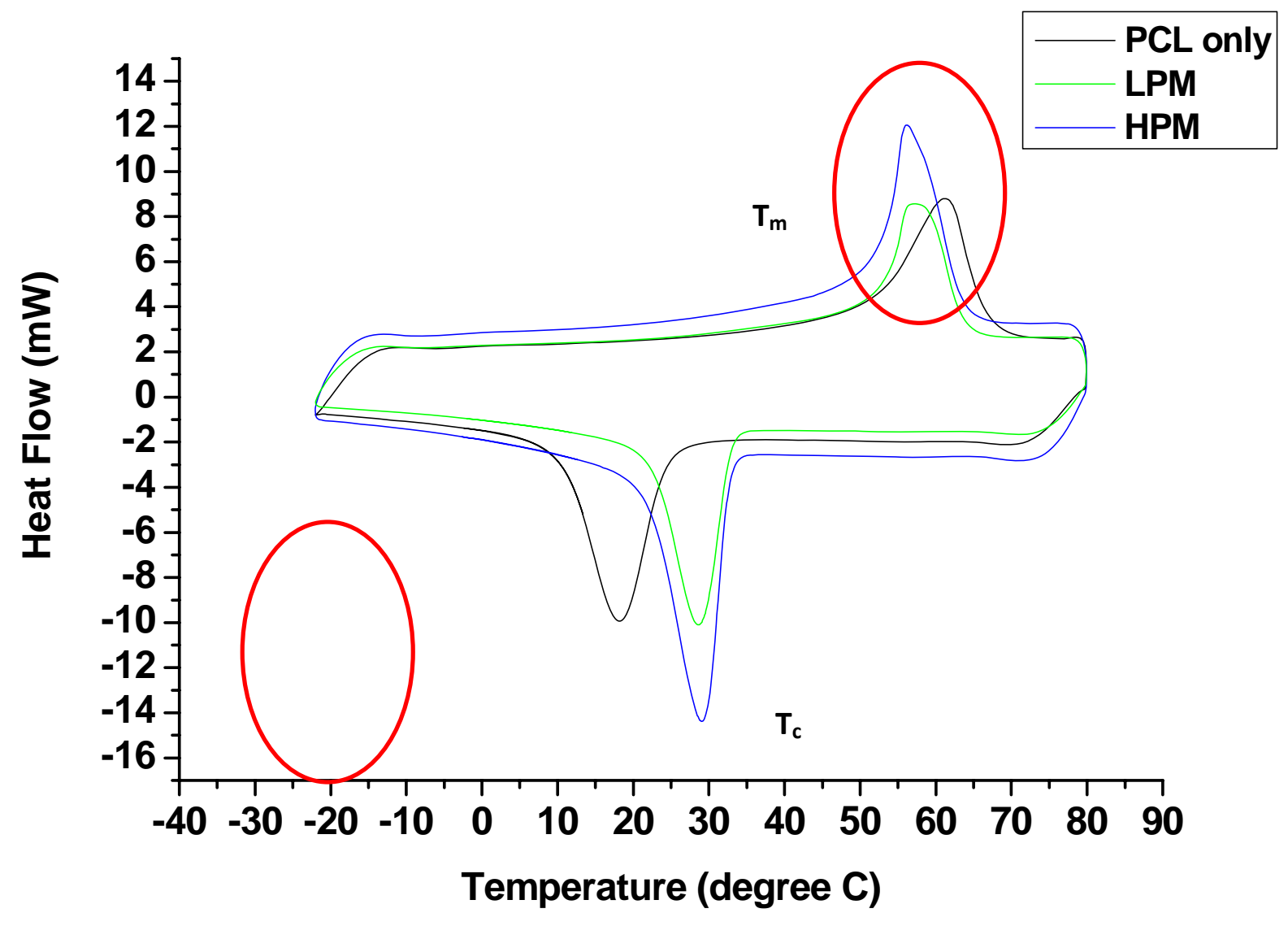


Figure 5

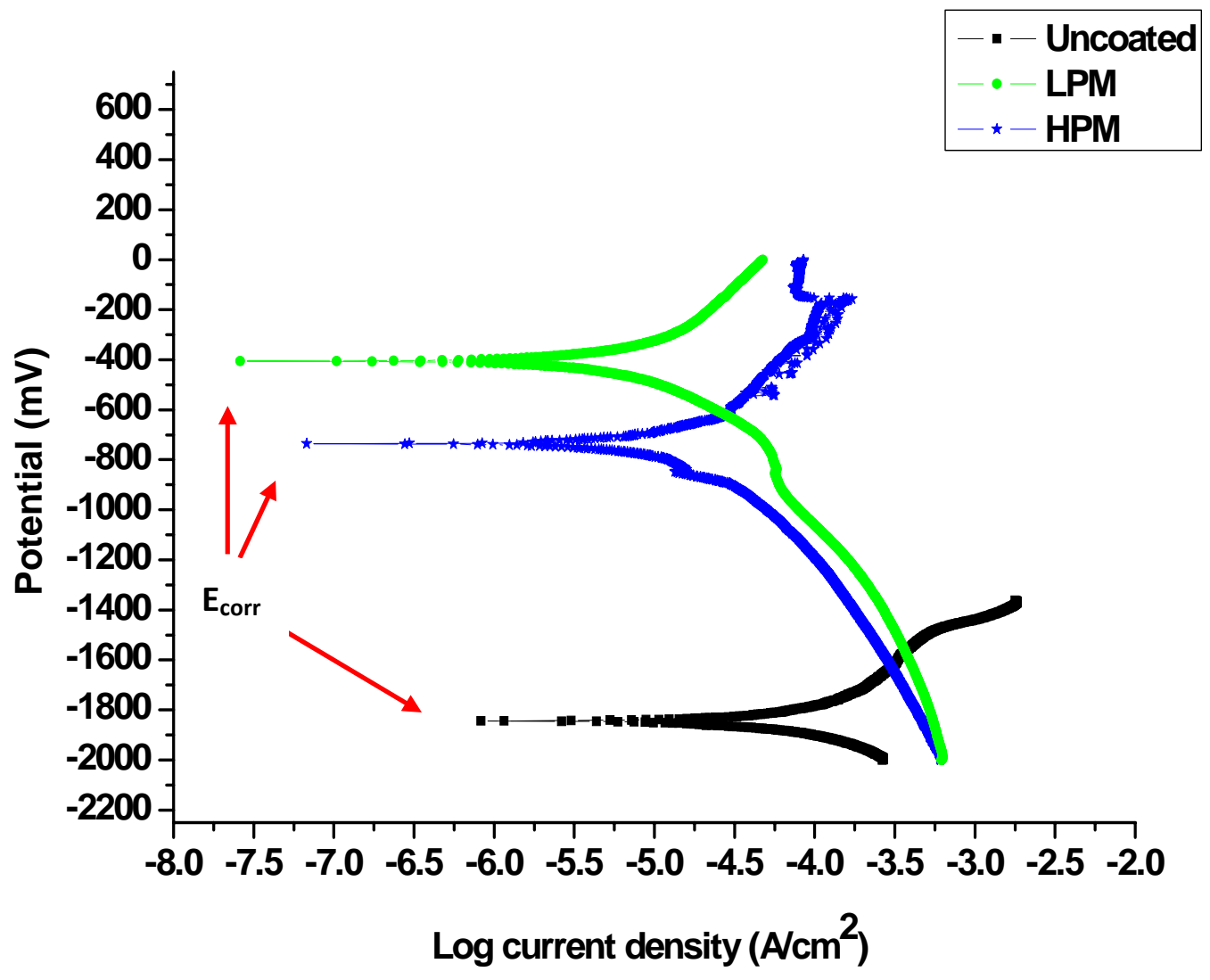


Figure 6

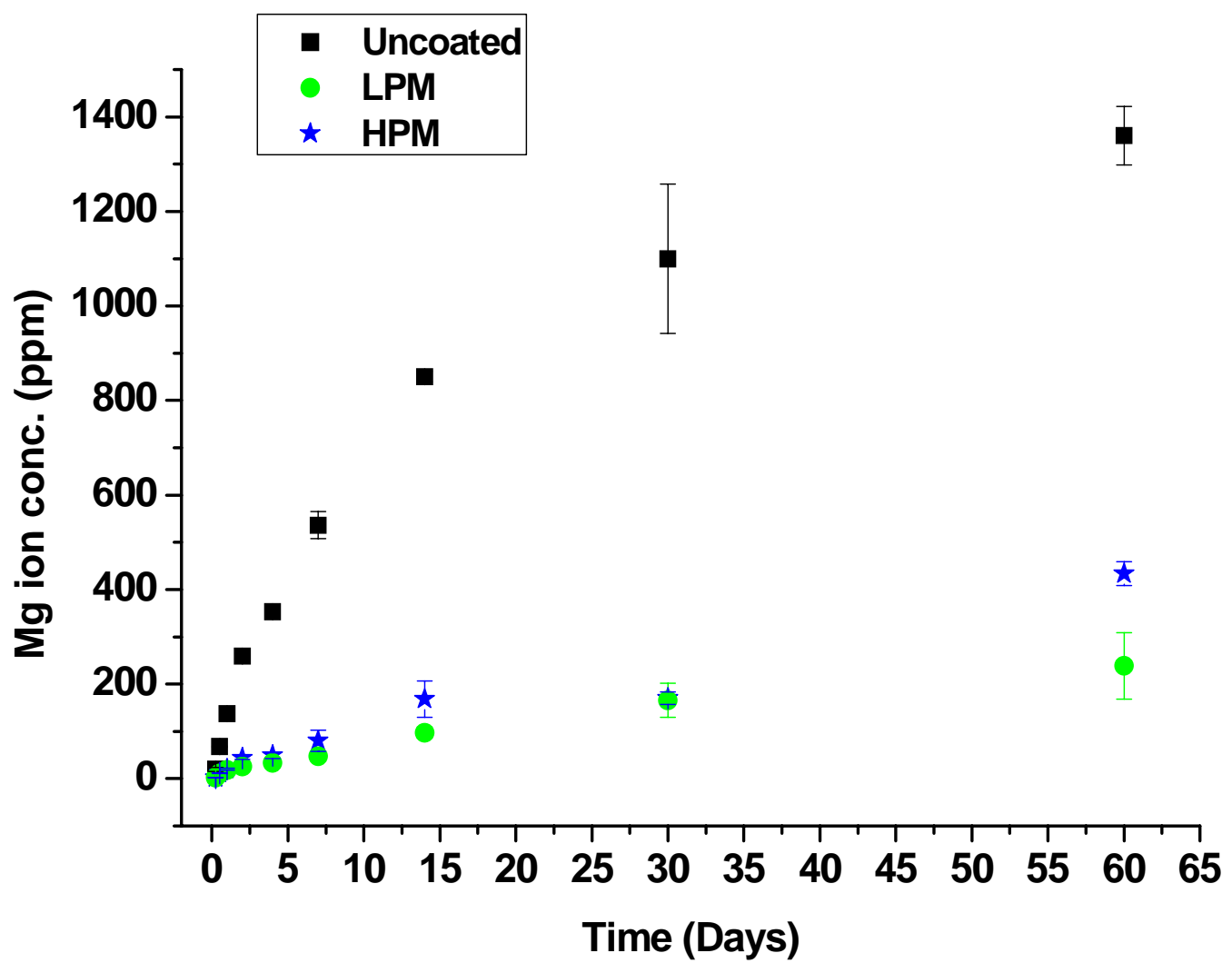


Figure 7

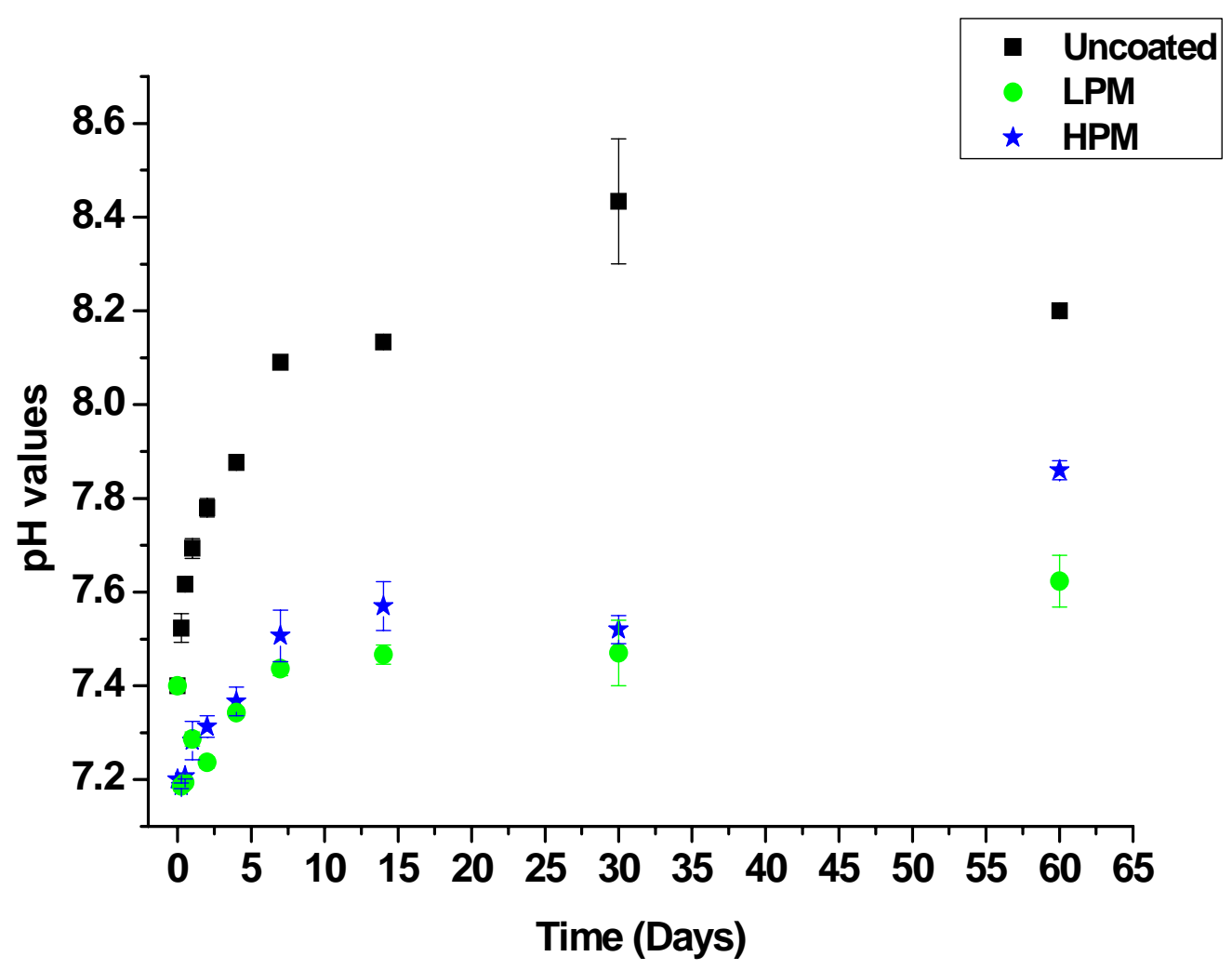


Figure 8

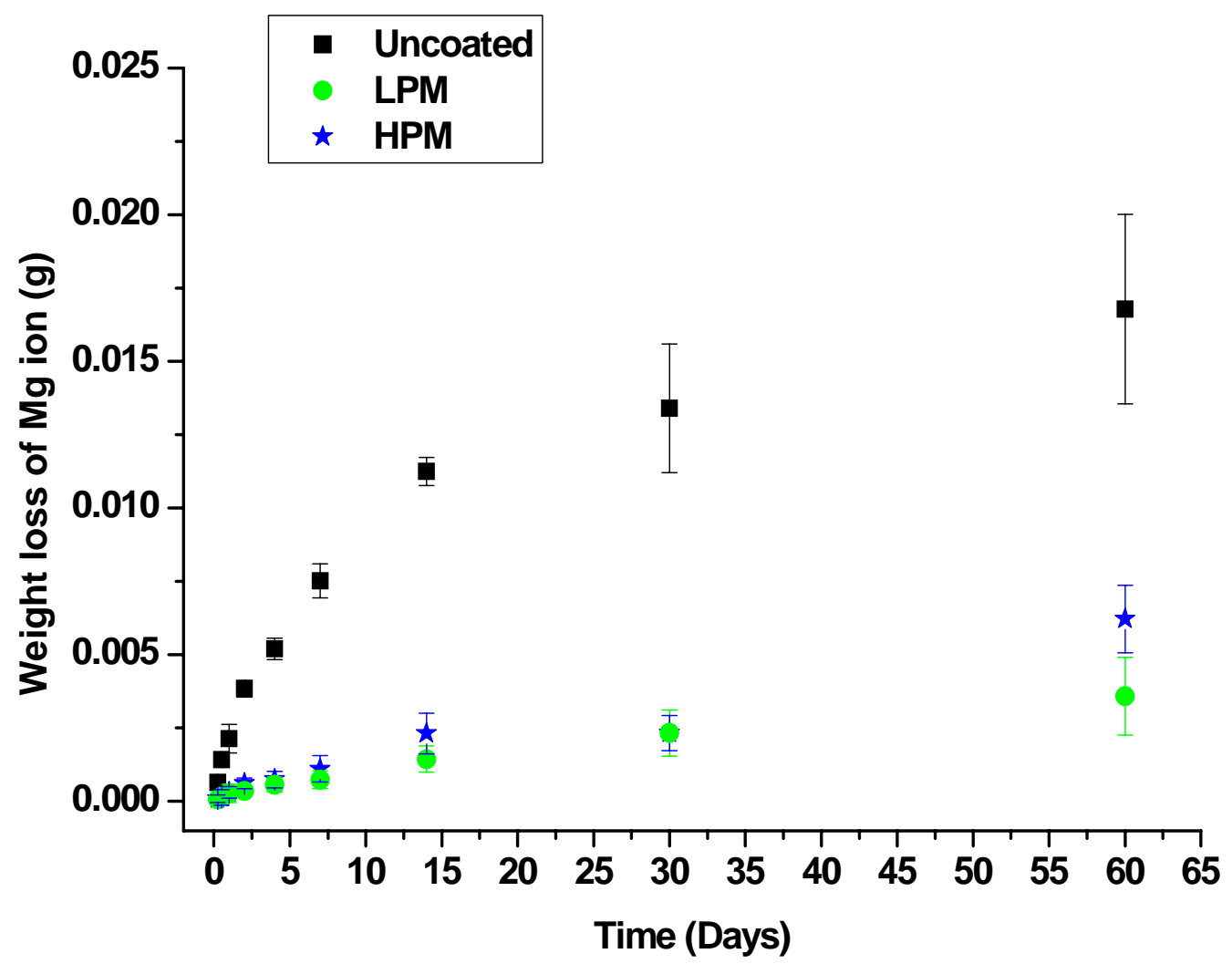


Figure 9

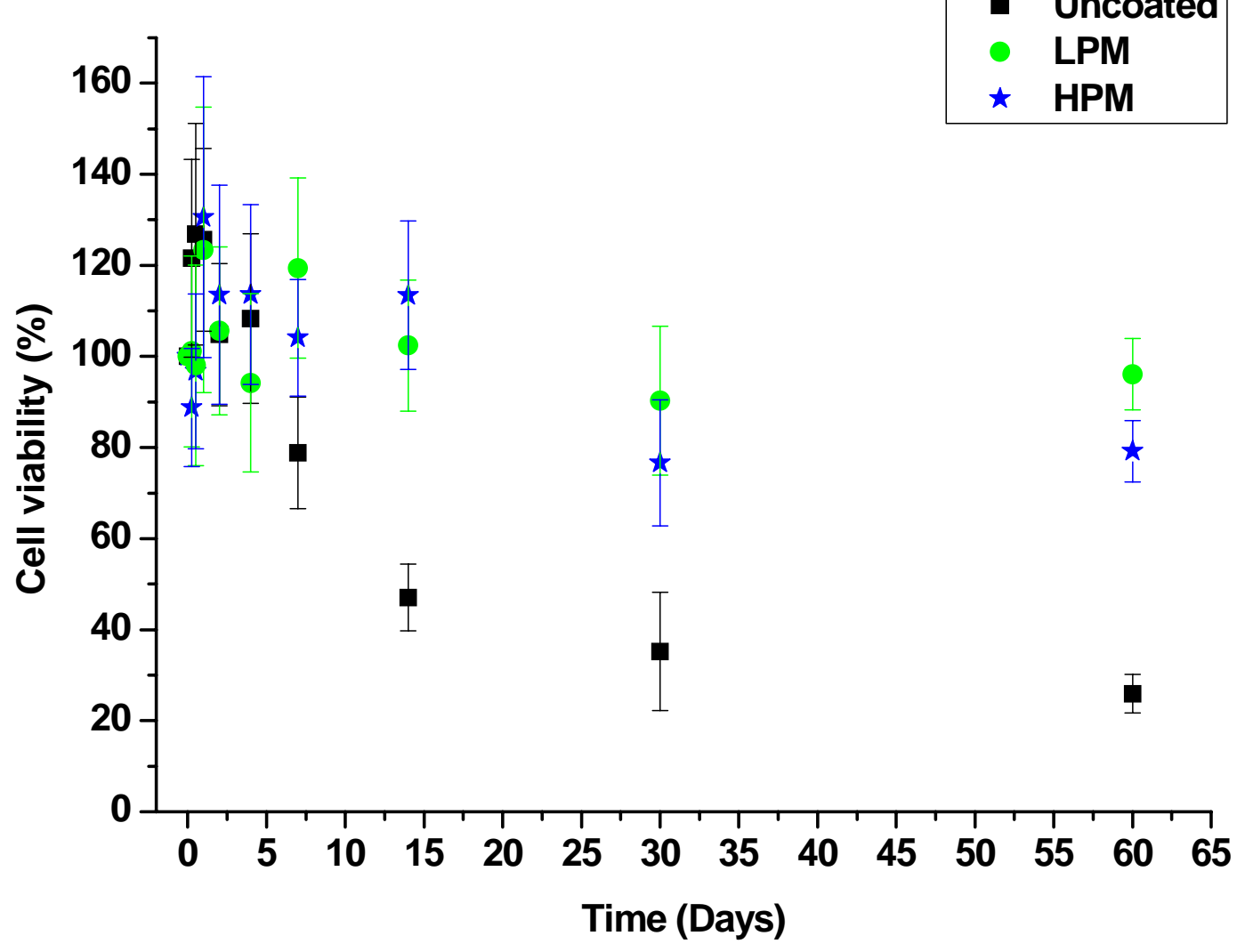


Figure 10
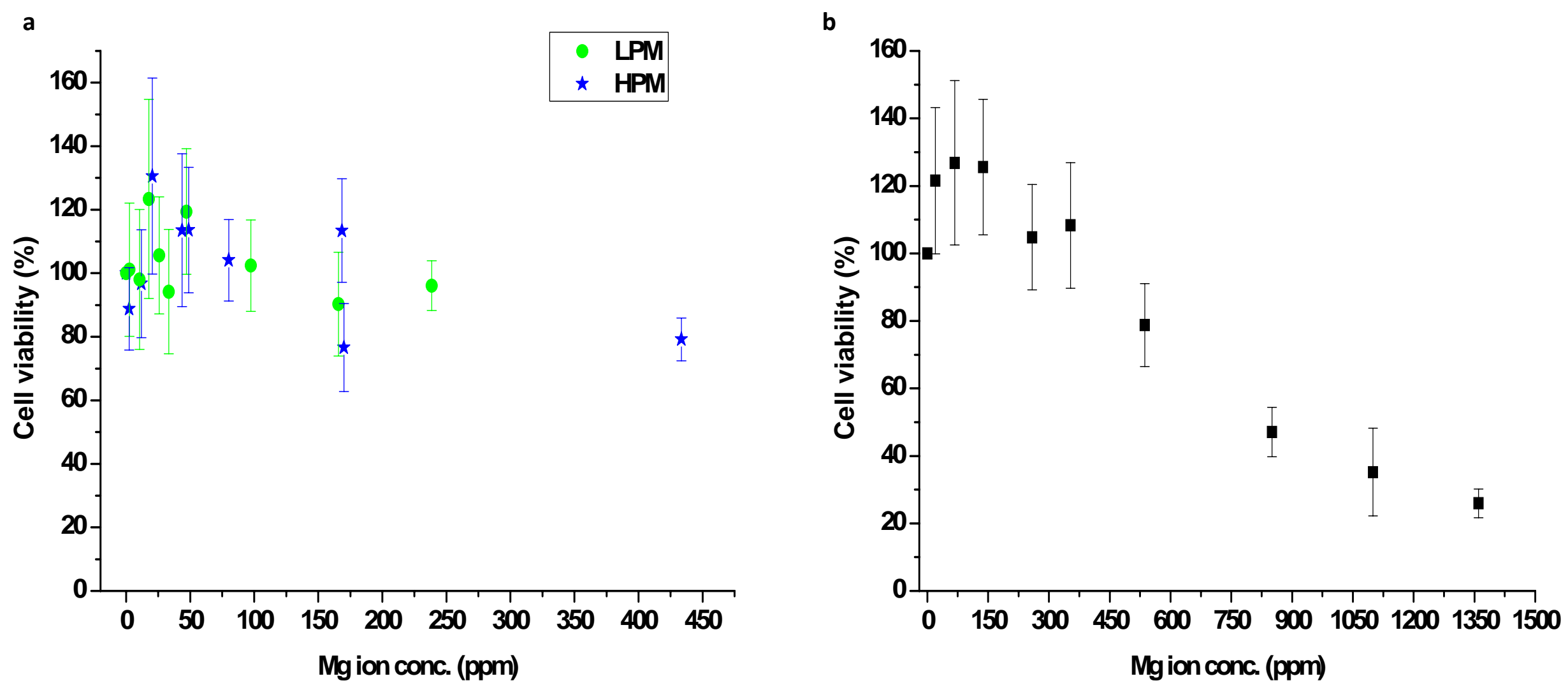


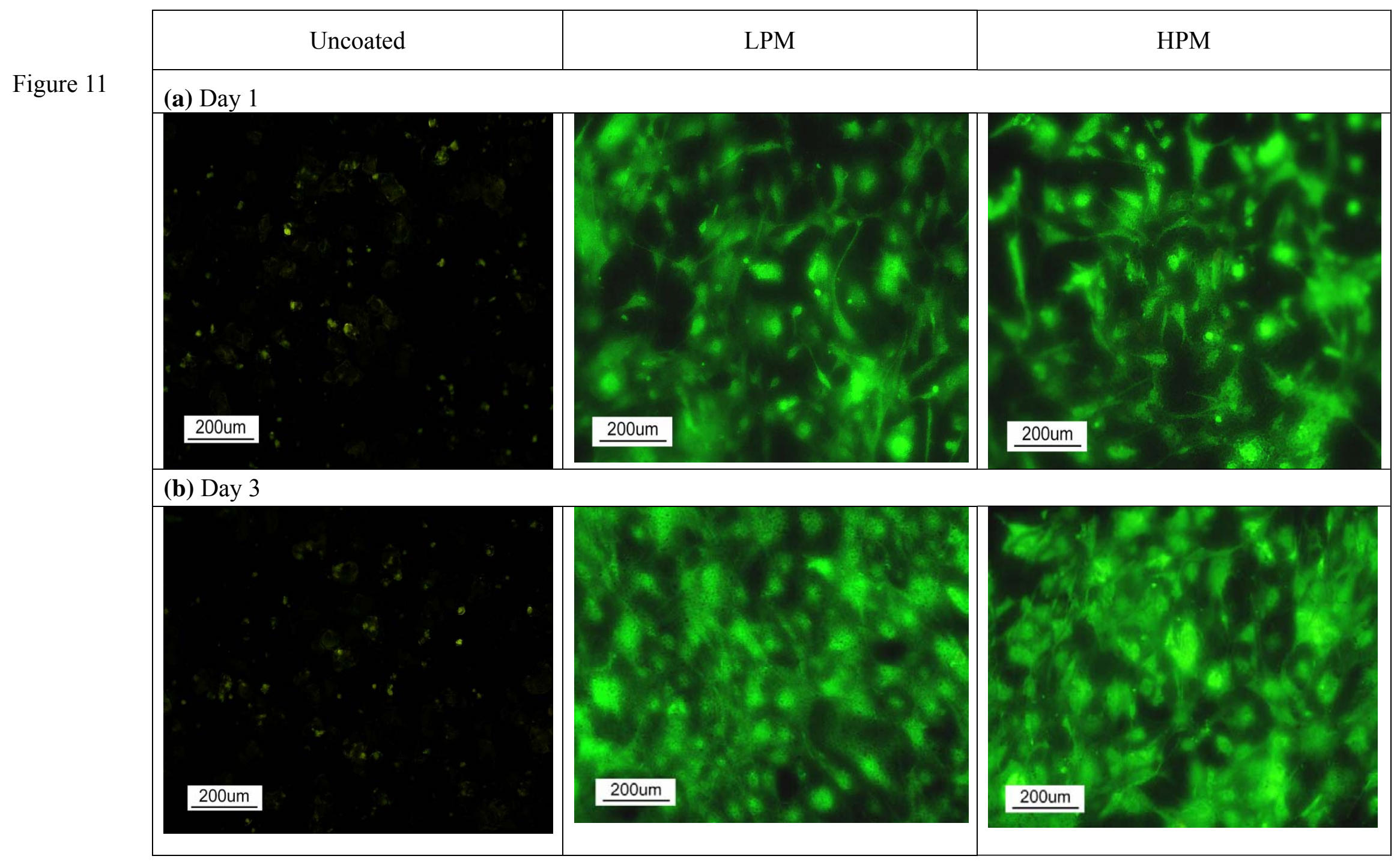


Figure 12

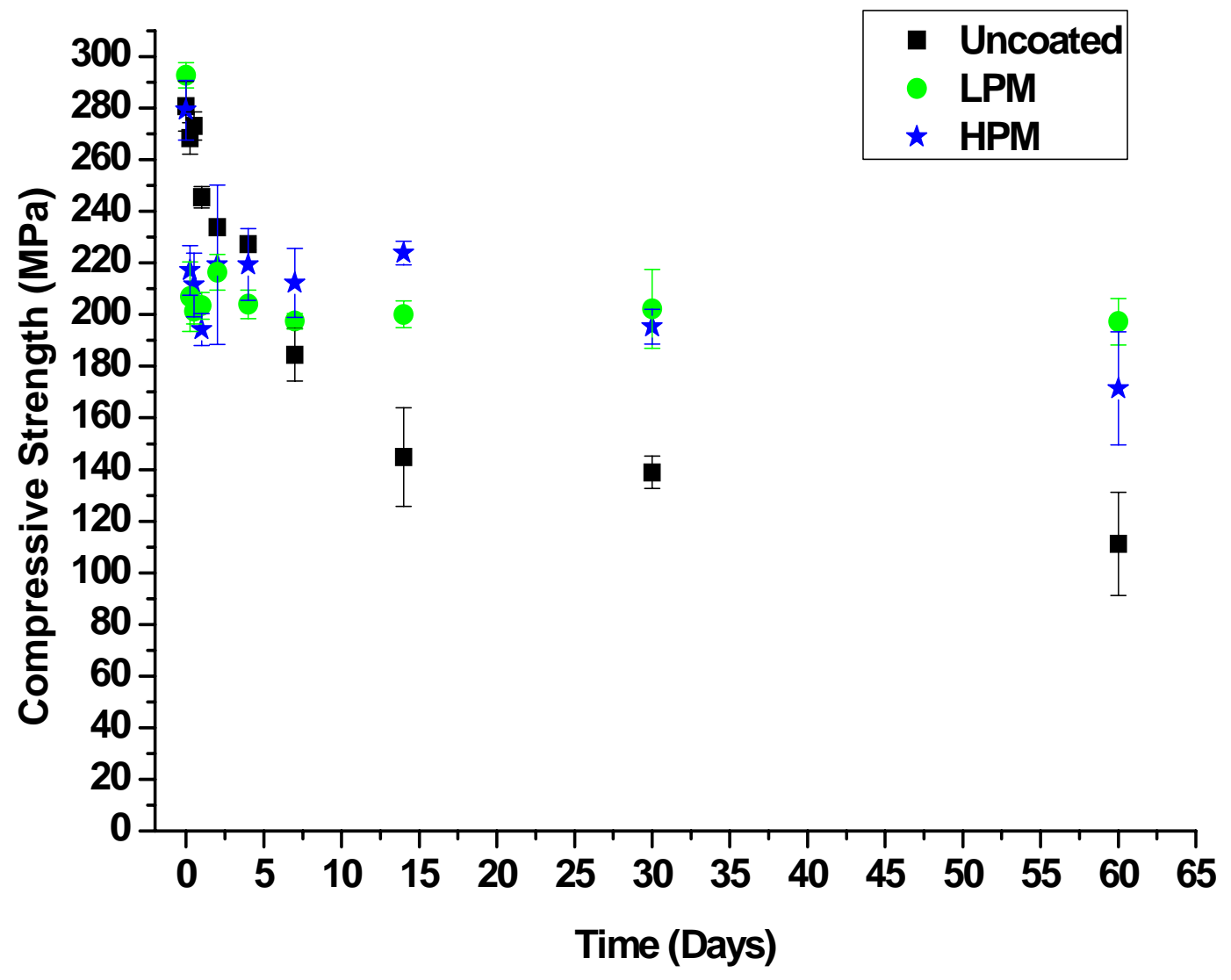




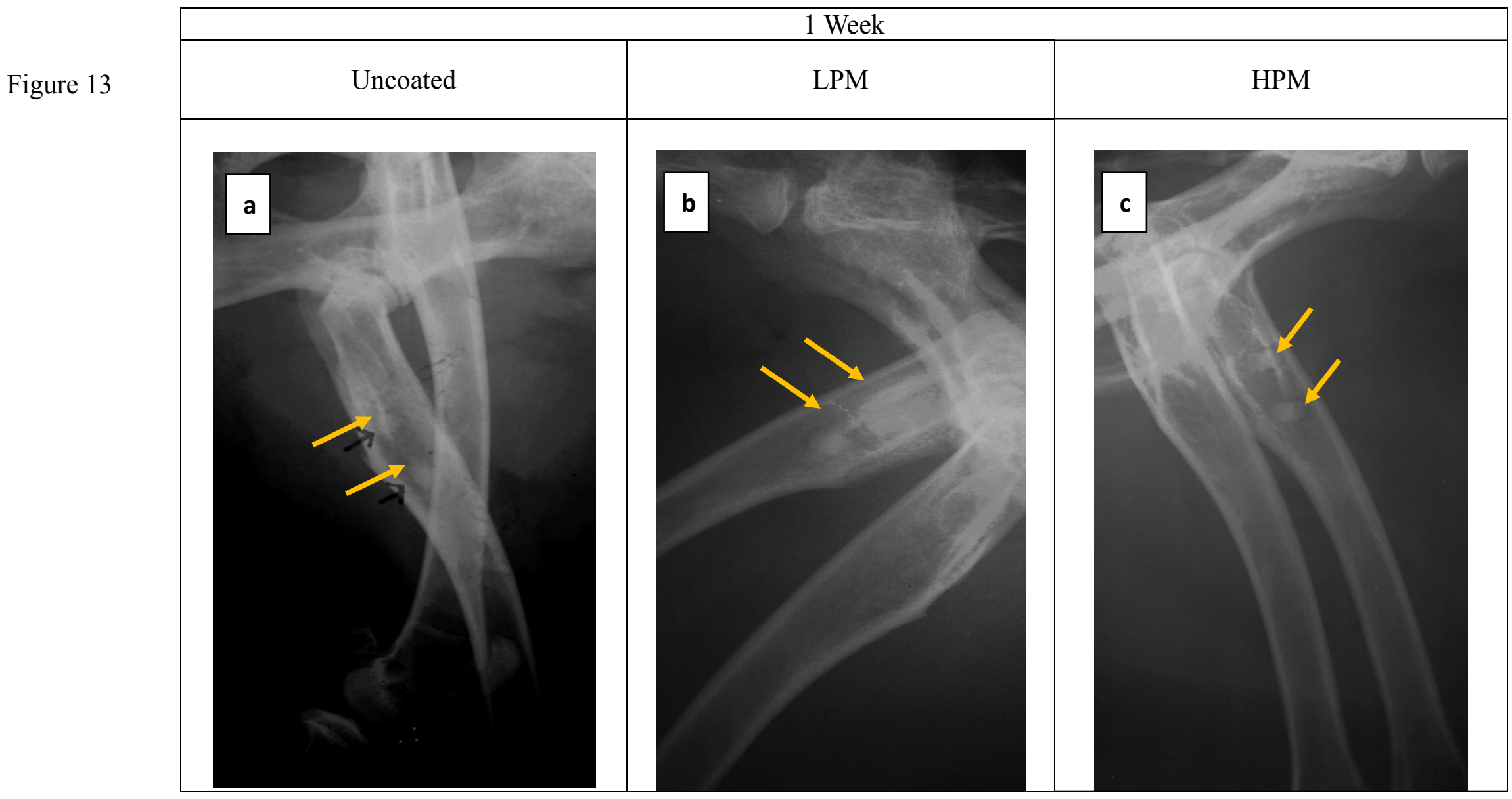




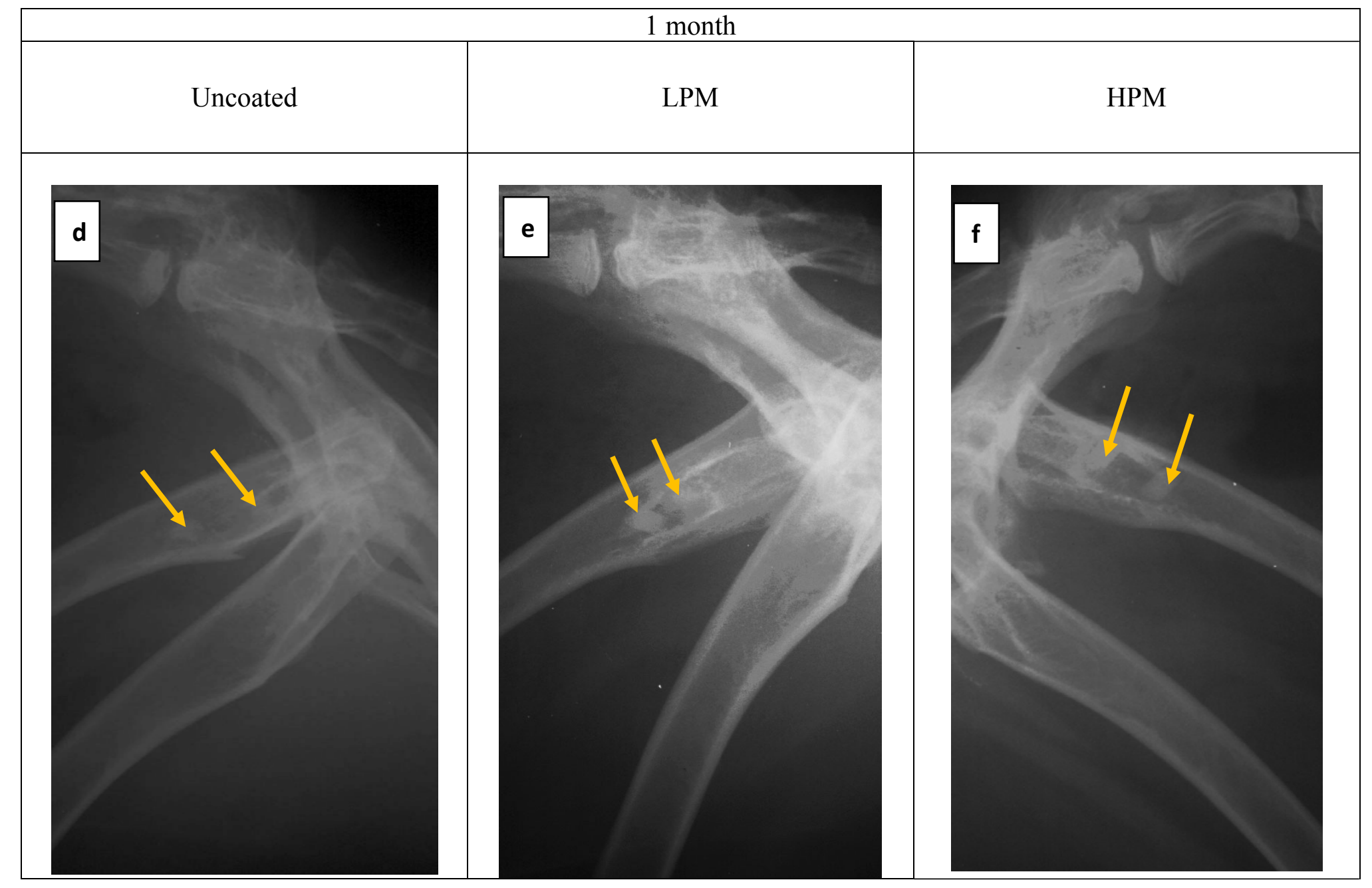




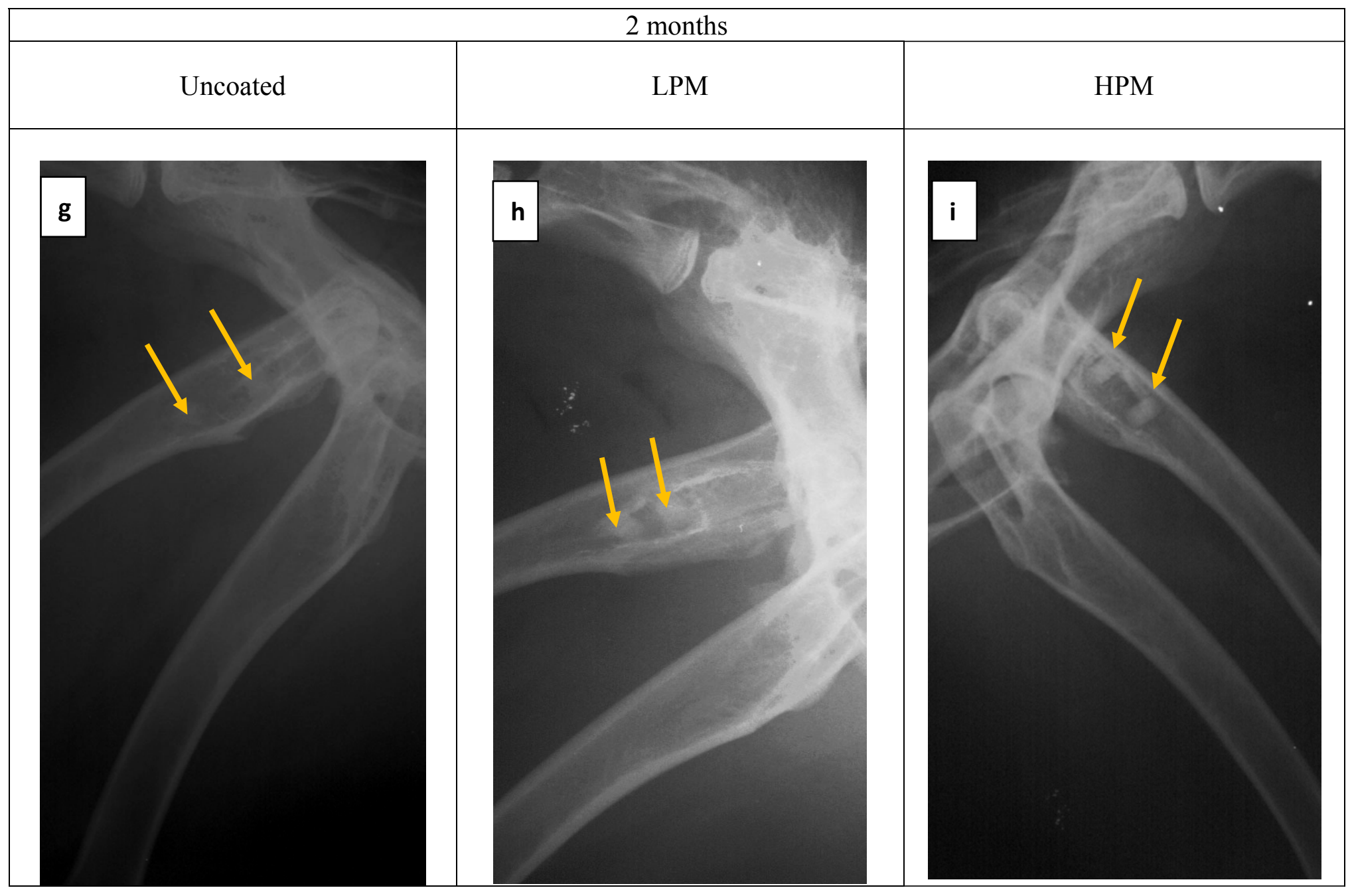


Figure 14

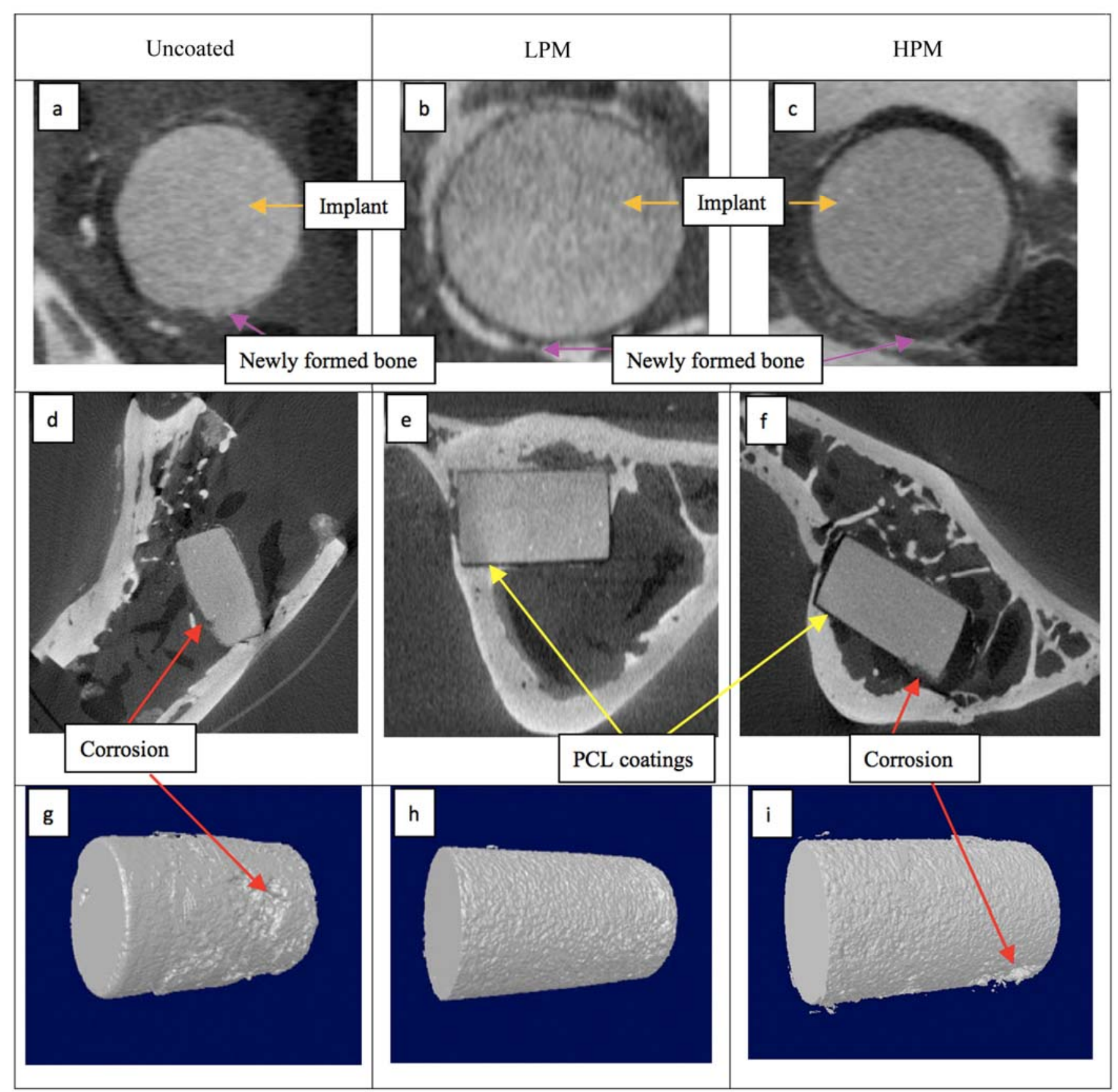


Figure 15
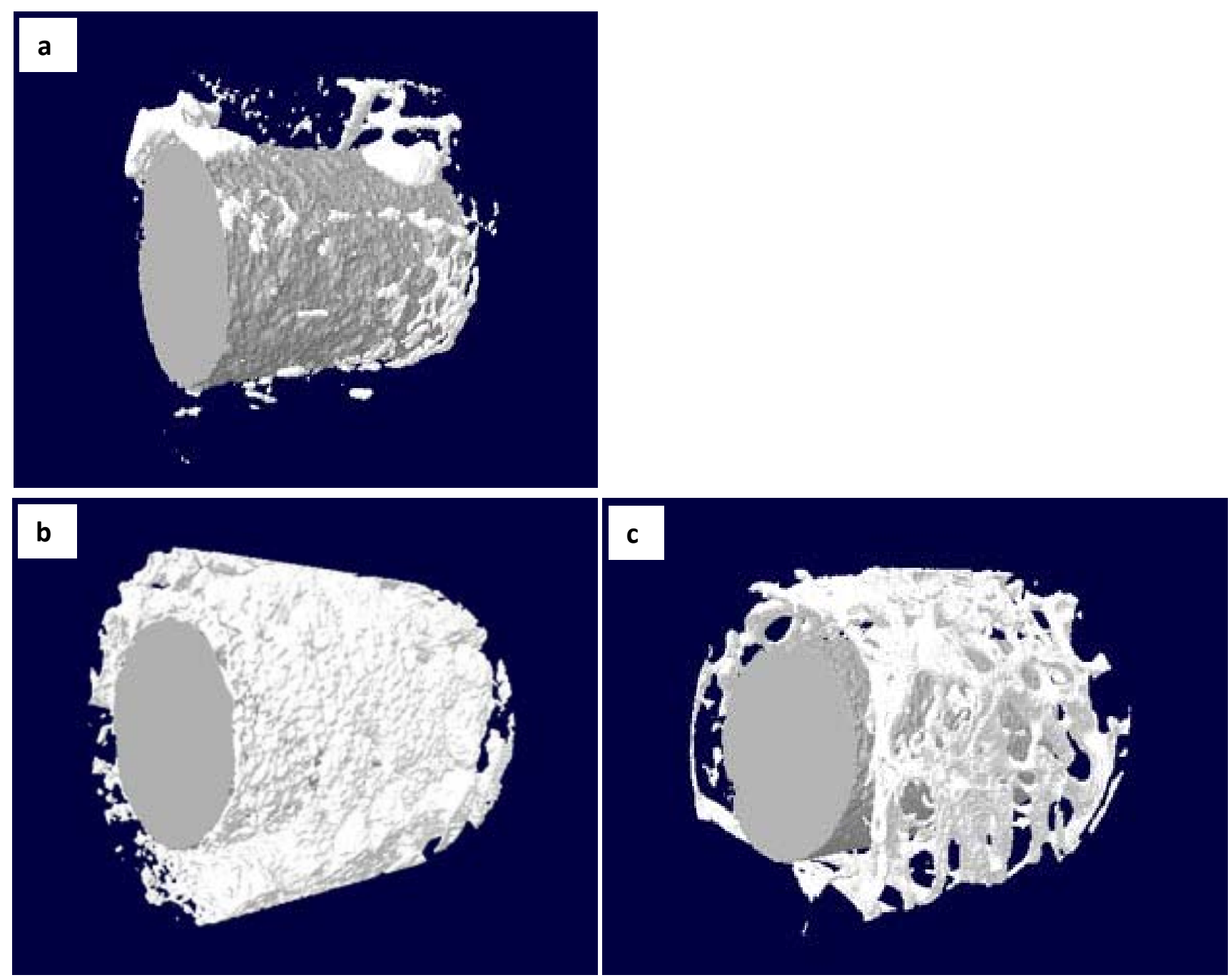
Figure 16

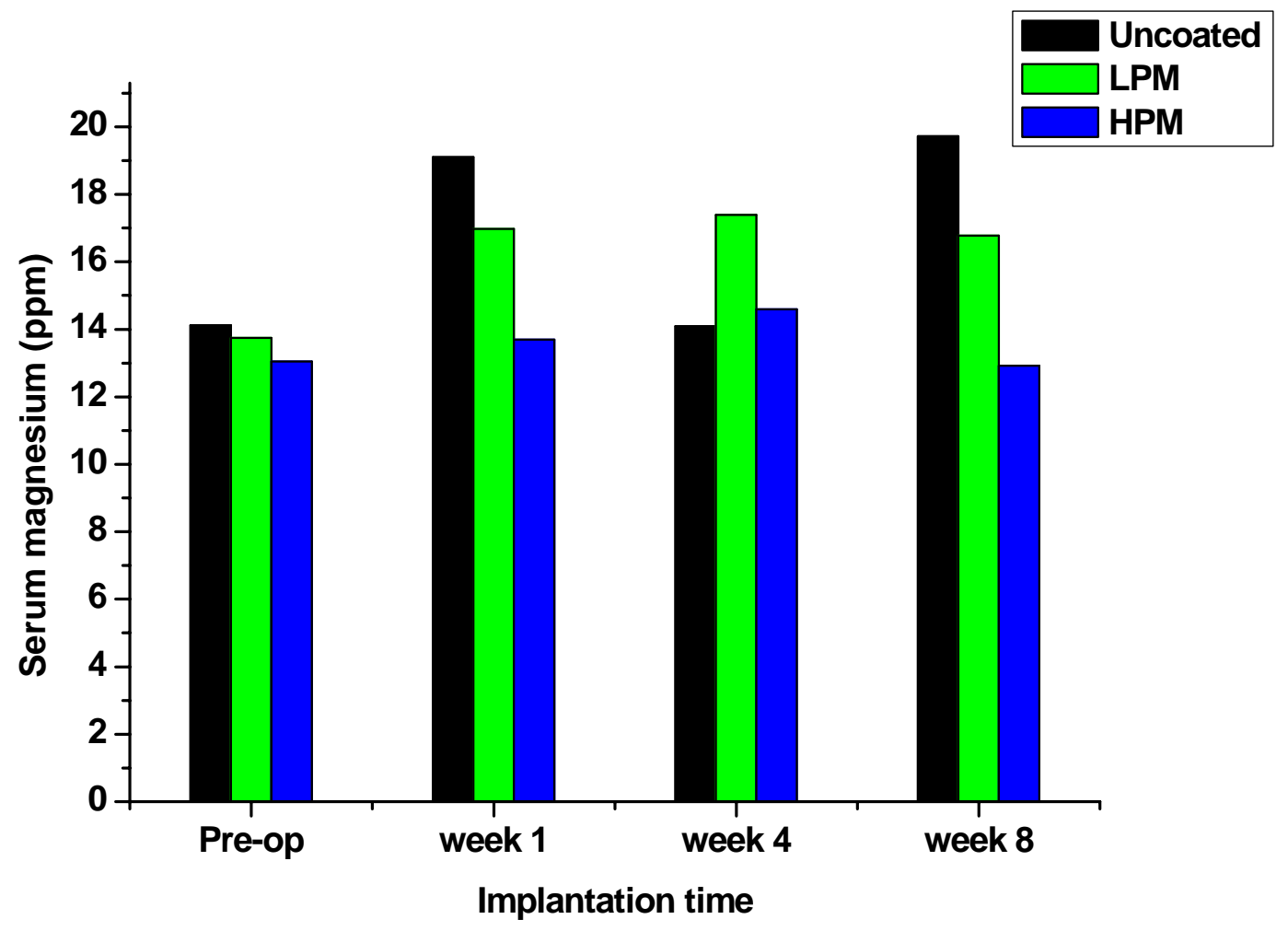


Figure 17
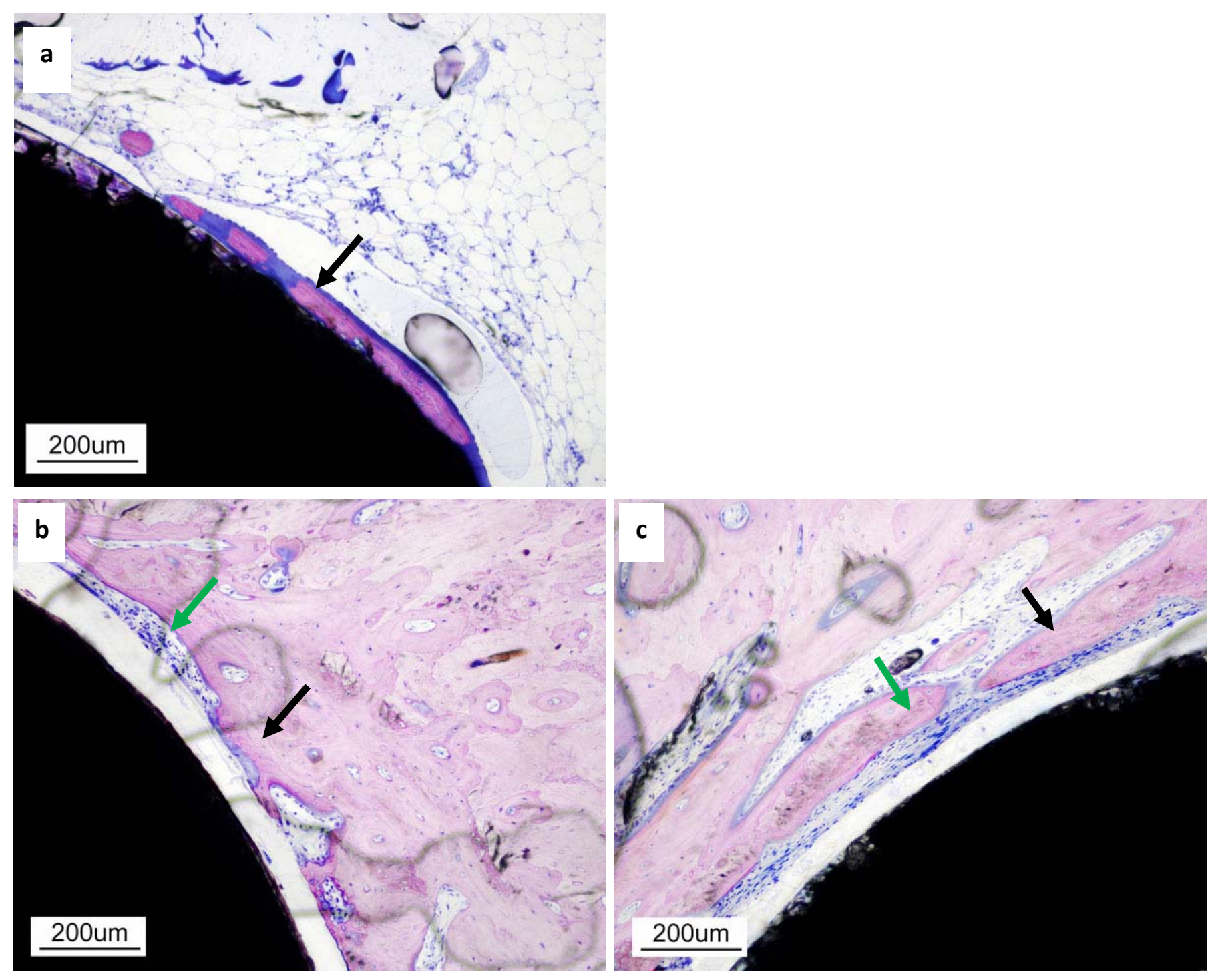
Table 1. Thermal properties of different PCL membranes determined by differential scanning calorimetry

\begin{tabular}{ccccc}
\hline Sample & $\mathrm{T}_{\mathrm{m}}\left({ }^{\circ} \mathrm{C}\right)$ & $\mathrm{T}_{\mathrm{c}}\left({ }^{\circ} \mathrm{C}\right)$ & $\Delta \mathrm{H}_{\mathrm{m}}(\mathrm{J} / \mathrm{g})$ & $\mathrm{X}_{\mathrm{c}}(\%)$ \\
\hline PCL only & 61.24 & 18.15 & 49.87 & 35.9 \\
LPM & 57.29 & 28.58 & 54.36 & 39.1 \\
HPM & 56.20 & 29.03 & 57.36 & 41.3 \\
\hline
\end{tabular}

$\mathrm{T}_{\mathrm{m}}$ represents the melting temperature; $\mathrm{T}_{\mathrm{c}}$ represents the crystallization temperature;

$\Delta \mathrm{H}_{\mathrm{m}}$ represents the change of melting of heat and $\mathrm{X}_{\mathrm{c}}$ represents the crystallinity

Table 2. Amounts of new bone volume and the remaining implant volume after 2 months implantation

\begin{tabular}{ccccc}
\hline Sample & $\begin{array}{c}\text { New bone } \\
\text { volume }\left(\mathrm{mm}^{3}\right)\end{array}$ & $\begin{array}{c}\text { Initial implant } \\
\text { volume }\left(\mathrm{mm}^{3}\right)\end{array}$ & $\begin{array}{c}\text { Final implant } \\
\text { volume }\left(\mathrm{mm}^{3}\right)\end{array}$ & $\begin{array}{c}\text { Implant volume } \\
\text { change }(\%)\end{array}$ \\
\hline Uncoated & 1.36 & 42.41 & 42.27 & -0.33 \\
LPM & 10.79 & 42.41 & 42.41 & 0 \\
HPM & 5.17 & 42.41 & 42.39 & -0.05 \\
\hline
\end{tabular}

